\title{
Bacteriophage-encoded virion-associated enzymes to overcome the carbohydrate barriers during the infection process
}

\author{
Agnieszka Latka ${ }^{1,2}$ - Barbara Maciejewska ${ }^{1}$ - Grazyna Majkowska-Skrobek ${ }^{1}$. \\ Yves Briers $^{2} \cdot$ Zuzanna Drulis-Kawa ${ }^{1}$
}

Received: 27 January 2017 /Revised: 23 February 2017 / Accepted: 4 March 2017 /Published online: 23 March 2017

(C) The Author(s) 2017. This article is published with open access at Springerlink.com

\begin{abstract}
Bacteriophages are bacterial viruses that infect the host after successful receptor recognition and adsorption to the cell surface. The irreversible adherence followed by genome material ejection into host cell cytoplasm must be preceded by the passage of diverse carbohydrate barriers such as capsule polysaccharides (CPSs), O-polysaccharide chains of lipopolysaccharide (LPS) molecules, extracellular polysaccharides (EPSs) forming biofilm matrix, and peptidoglycan (PG) layers. For that purpose, bacteriophages are equipped with various virion-associated carbohydrate active enzymes, termed polysaccharide depolymerases and lysins, that recognize, bind, and degrade the polysaccharide compounds. We discuss the existing diversity in structural locations, variable architectures, enzymatic specificities, and evolutionary aspects of polysaccharide depolymerases and virion-associated lysins (VALs) and illustrate how these aspects can correlate with the host spectrum. In addition, we present methods that can be used for activity determination and the application potential of these enzymes as antibacterials, antivirulence agents, and diagnostic tools.
\end{abstract}

Keywords Bacteriophages · Polysaccharide depolymerases · Virion-associated lysins

Agnieszka Latka and Barbara Maciejewska contributed equally to this work.

Zuzanna Drulis-Kawa

zuzanna.drulis-kawa@uwr.edu.pl

1 Department of Pathogen Biology and Immunology, Institute of Genetics and Microbiology, University of Wroclaw, Przybyszewskiego 63/77, 51-148 Wroclaw, Poland

2 Laboratory of Applied Biotechnology, Department of Applied Biosciences, Ghent University, Valentin Vaerwyckweg 1, 9000 Ghent, Belgium

\section{Introduction}

Bacteriophages (phages) are bacterial predators. Every phage infection is initiated by adsorption (i.e., the attachment of the phage particle to the bacterial host cell), which is characterized by the specific recognition of a receptor located on the bacterial cell surface. Subsequently, phages have to penetrate the bacterial cell envelope and will eventually eject their viral genome into the cytoplasm (Weinbauer 2004). On the way to the bacterial cytoplasm, phages have to overcome different carbohydrate barriers. Some bacteria produce capsular polysaccharides (CPSs; also called K-antigens), which are tightly attached to the cell. Other bacteria secrete slime with extracellular polysaccharides (EPSs) to the environment during biofilm formation (Schmid et al. 2015). Both CPS and EPS have a huge diversity in composition, not only within a bacterial genus but also within a species, and this composition can also vary dependent on the growth phase and environmental conditions (Corbett and Roberts 2008; Leiman and Molineux 2008). Gram-negative bacteria are characterized by an outer membrane composed of lipopolysaccharide (LPS) molecules with a highly variable O-polysaccharide (Oantigen), whereas Gram-positive bacteria have essential components such as (lipo)teichoic acids embedded in peptidoglycan (PG). These polysaccharides are often a primary receptor, along with other protruding cell wall structures such as pili and flagella. Bacteriophages have evolved various virion-associated carbohydrate active enzymes, termed polysaccharide depolymerases, that recognize, bind, and degrade the polysaccharide compounds to gain access to the initially inaccessible bacterial cell surface receptor (Leiman et al. 2007; Leiman and Molineux 2008; Li et al. 2016). This secondary receptor (co-receptor) can be an outer membrane protein, a cell wall embedded protein (structural proteins, transport channels, enzymatic and secreting proteins), or a distal part of the exopolysaccharides (Nilsson et al. 2000; Bertozzi Silva et al. 2016). Binding of this receptor will 
eventually trigger DNA ejection (Leiman and Molineux 2008). To transfer the genome to the bacterial cytoplasm, bacteriophages have to overcome another rigid carbohydrate barrier, i.e., the PG. This structure comprises up to 40 layers in case of Gram-positive bacteria and 1-3 layers in case of Gram-negative bacteria. Whereas the chemotype of the PG of Gram-negative bacteria is conserved (A1 $\gamma$ ), the PG composition of Gram-positive bacteria varies significantly in peptide composition, cross-link, and modification of the glycan chain (Briers et al. 2007b). Therefore, phage particles are equipped with a virion-associated lysin. In contrast to the lysis phase where PG is extensively degraded by endolysins, the virion-associated lysins only locally puncture a hole in the PG, which is sufficiently large to eject the phage DNA into the cytoplasm.

This review gives an overview about the recent knowledge of virion-associated carbohydrate active enzymes. Whereas virion-associated lysins are a prerequisite for every phage as PG is an inevitable barrier, polysaccharide depolymerases provide the phages with tools to have a competitive advantage in niches (e.g., in biofilms, these enzymes allow to gain access to the microcolonies and to infect embedded bacteria (Abedon 2012) and to differentiate in host spectrum). The study on LPS-degrading depolymerase suggested that the low enzyme kinetics may be correlated with O-chain degradation important for detachment of released progeny, rather than for initial adsorption step (Steinbacher et al. 1996). Both groups of carbohydrate active enzyme share common features such as a customized enzyme specificity evolved throughout a continuous arm race between phage and host and their structural location. Some reviews dealing with these phage-encoded, virion-associated enzymes have been published recently, particularly focusing on general characteristics and biomedical applications (Drulis-Kawa et al. 2012, 2015; Yan et al. 2014) or on virion-associated peptidoglycan hydrolases (VAPGHs) (Rodríguez-Rubio et al. 2013a). Pires et al. (2016) recently provided an overview of 160 putative depolymerases in 143 phages infecting 24 genera of bacteria based on an extensive in silico analysis. Here, we present a summary of experimentally confirmed polysaccharide depolymerases and virion-associated lysins (VALs) and focus on the main characteristics of the corresponding genes, their protein structure, their location within the virion particle, their mode of action and specificity, evolutionary aspects, methods for activity determination, and potential applications.

\section{Polysaccharide depolymerases}

The hallmark feature for the presence of phage-encoded polysaccharide depolymerases was firstly described in 1956 as the plaque-surrounding halos, which increase in diameter over time of incubation while the plaque size remains constant. The depolymerases responsible for the degradation of CPS,
EPS, or O-polysaccharide can be virion-associated as an integral part of the virion particle or can be in a soluble form, being released during bacterial cell lysis without being integrated in a phage particle (Adams and Park 1956; Stirm et al. 1971). Both can freely diffuse and cause a time-dependent polysaccharide degradation resulting in the typical halo-like appearance around plaques. In spite of polysaccharide degradation, phages do not establish an infection since the bacterial cells in the halo are not actively propagating.

\section{Enzymatic activity and specificity of polysaccharide depolymerases}

Bacteriophage-encoded depolymerases can be divided into two main classes according to their mechanism of action, i.e., hydrolases (EC 3) and lyases (EC 4), both resulting in the cleavage of polysaccharides into soluble oligosaccharides and the breakdown of the carbohydrate barrier. Within both classes, there is a tremendous variation in specificity responding to the large existing diversity in bacterial polysaccharides (CPS, EPS, O-polysaccharides). This high specificity usually contributes to the narrow host spectrum. The majority of hydrolases belong to the group of O-glycosyl hydrolases (EC 3.2.1), which use a water molecule to cleave specifically the O-glycosidic bonds of the polysaccharide. This group comprises sialidases, rhamnosidases, levanases, xylanases, and dextranases (Davies and Henrissat 1995; Pires et al. 2016). Polysaccharide depolymerases for which experimental data are available are mainly derived from phages propagating on the most common human pathogens (Table 1).

Probably, the best studied depolymerases are the sialidases or endo-N-acetylneuraminidases originating from Escherichia coli K1 specific bacteriophages such as K1A, K1E, K1F, K1-5, 63D, CUS-3, $\Phi 1.2$, and $\Phi 92$ (Kwiatkowski et al. 1983; Petter and Vimr 1993; Gerardy-Schahn et al. 1995; Long et al. 1995; Machida et al. 2000; Scholl et al. 2001; Muhlenhoff et al. 2003; Stummeyer et al. 2005; Stummeyer et al. 2006; Jakobsson et al. 2007; Schwarzer et al. 2012). Sialidases hydrolyze internal $\alpha-2,8$-linkages in capsular polysialic acid. Proteins possessing endosialidase domains have also been found in Klebsiella phages KLPN1 and 0507-KN2-1 (Hsu et al. 2013; Hoyles et al. 2015) (Table 1). Rhamnosidases are enzymes able to cleave the $\alpha-1,3$ O-glycosidic bond between L-rhamnose and D-galactose present in the O-antigen of Salmonella LPS. They have been described as tailspikes in phages specific for Salmonella (P27, KB1, P22, 9NA, Det7, Epsilon15) and Shigella (Sf6) (Wollin et al. 1981; Steinbacher et al. 1996, 1997; Baxa et al. 1996; Chua et al. 1999; Freiberg et al. 2003; Walter et al. 2008; Chang et al. 2010; Guichard et al. 2013). $E$. coli LPS-degrading enzymes were found as endo-Nacetylglucosaminidase and endo- $\alpha-1,3$-mannosidase in HK620 and Omega8 phages, respectively (Barbirz et al. 2008; Prehm and Jann 1976) (Table 1). A levanase catalyzes hydrolysis of 


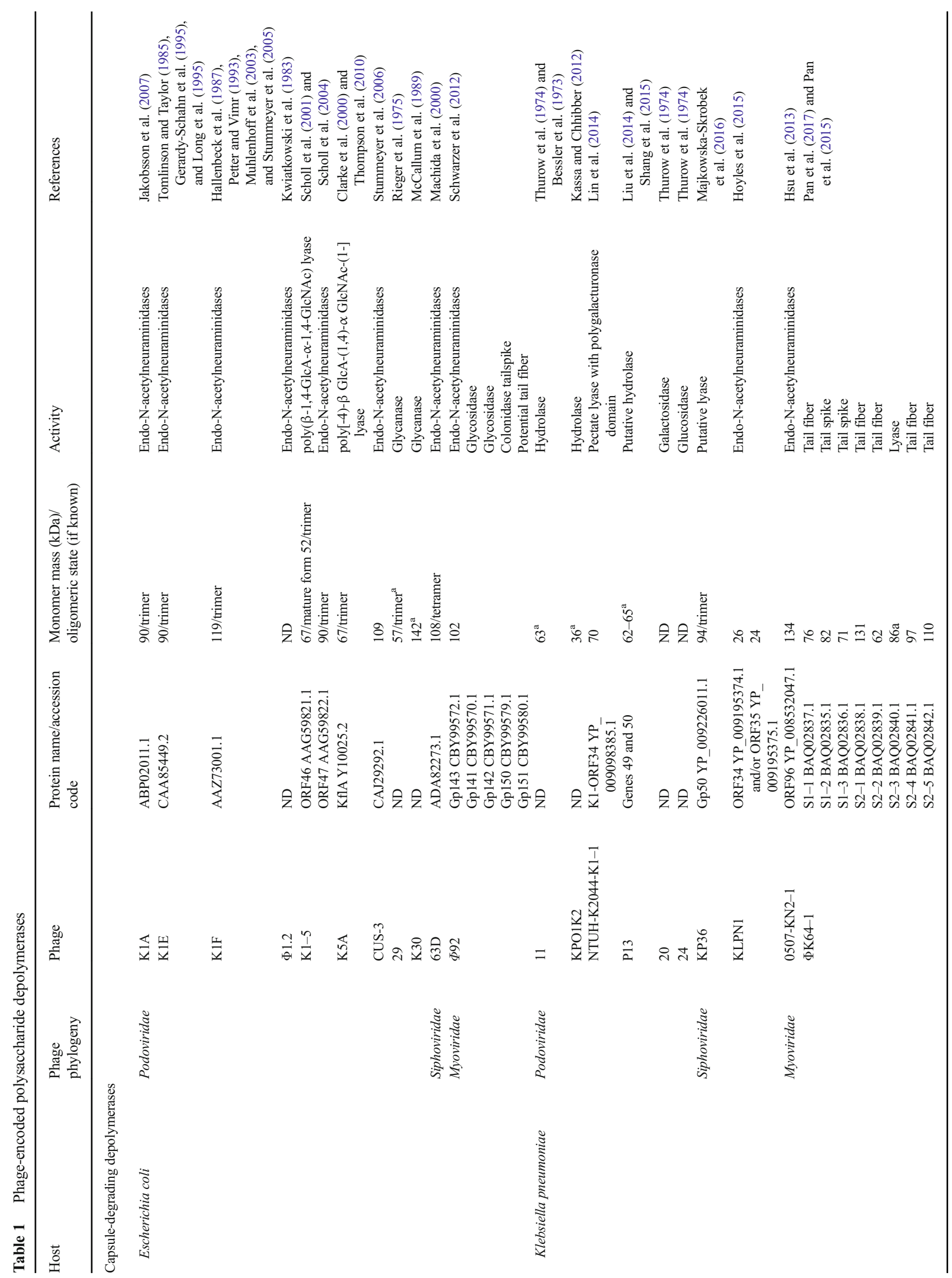




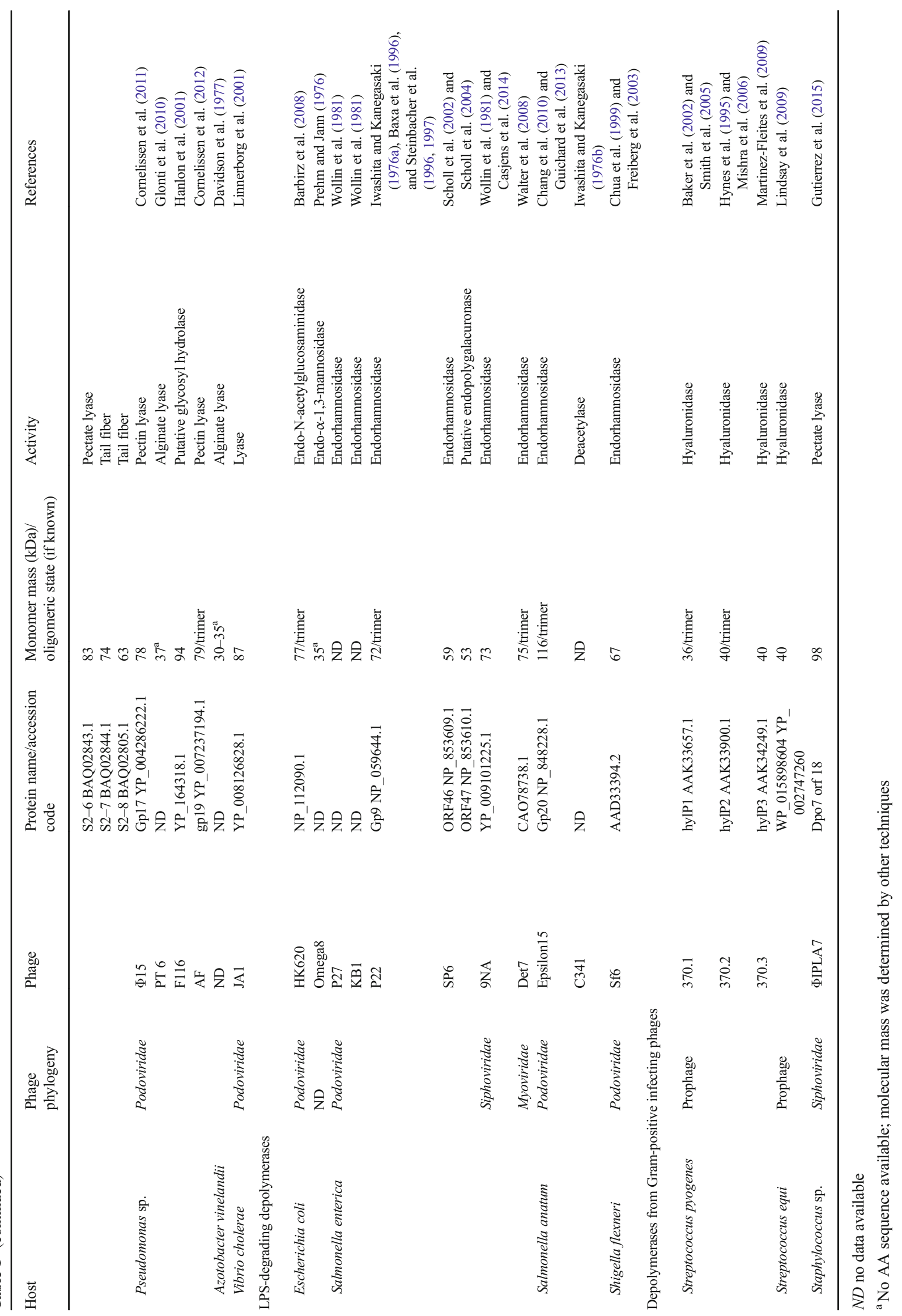


the $\beta-2,6$-bond between fructose monomers in levan, which is present in Bacillus biofilms and has been identified in Bacillus phage SP10. A xylanase responsible for hydrolysis of the $\beta-1,4$ bonds within xylan has been identified in the Caulobacter phage $\mathrm{Cr} 30$, while a dextranase cleaving the $\alpha$-1,6-linkages between glucose units in dextran is predicted in Lactobacillus phage ФPYB5 (Pires et al. 2016). Some virion-associated depolymerases do not depolymerize polysaccharides but cleave polypeptides (EC 3.4) or lipids (EC 3.1), responding to the different nature of some bacterial capsules. A peptidase enzyme digesting the poly- $\gamma$-glutamate capsular polypeptide of Bacillus sp. has been experimentally verified for Bacillus phage $\Phi$ NIT1 (Kimura and Itoh 2003). Pires et al. (2016) predicted also virionassociated lipases (triacylglycerol hydrolases) in eight Cellulophaga phages and one Pseudomonas phage, but experimental validation is currently lacking. A last group of virionassociated depolymerases with hydrolytic activity are LPS deacetylases in the tailspikes of the Vi phages (II and III) as well as those from Salmonella anatum phage c341, which deacetylate the O-antigen rather than breaking the polysaccharide chain (Iwashita and Kanegasaki 1976b).

Other polysaccharide depolymerases belong to the class of lyases, which differentiate from hydrolases as they cleave a glycosidic bond by $\beta$-elimination with the concomitant introduction of new double bond and without the use of a water molecule. Precisely, this group covers widespread hyaluronate, pectate/pectin, and alginate lyases and the specific K5 lyase (Sutherland 1995). Bacteriophage-encoded hyaluronidases (hyaluronate lyases) cleave the $\beta-1,4$ bonds between the subunits of hyaluronic acid and were found in prophages invading Streptococcus pyogenes and S. equi, which are both encapsulated by hyaluronic acid (Hynes et al. 1995; Ferretti et al. 2001; Baker et al. 2002; Smith et al. 2005; Mishra et al. 2006; Martinez-Fleites et al. 2009; Lindsay et al. 2009) (Table 1). Those enzymes are also used by the lysogenic host bacterium as a virulence factor to invade and penetrate human tissues. Pectate/pectin lyases are characterized by cleavage of the $\alpha-1,4$ bonds of polygalacturonic acid. Enzymes possessing such domain have been described for Pseudomonas phages $\Phi 15$ and AF (Cornelissen et al. 2011, 2012), Klebsiella phages (NTUH-K2044-K1-1, KP36) (Lin et al. 2014; Majkowska-Skrobek et al. 2016), Vibrio phage JA1 (Linnerborg et al. 2001), and Staphylococcus phage vB_SepiS- $\Phi I P L A 7$ (Gutierrez et al. 2015) (Table 1). Alginate lyases (mannuronate or guluronate lyases) characteristic for Pseudomonas and Azobacter phages (PT6) are able to degrade the $\alpha-1,4$ bond of alginate, a linear polysaccharide of $\beta$-D-mannuronate, and its C5 epimer $\alpha$-L-guluronate common for mucoid strains infecting cystic fibrosis patients (Davidson et al. 1977; Wong et al. 2000; Glonti et al. 2010) (Table 1$)$. The E. coli $\mathrm{K} 5$ capsular polysaccharide poly( $\beta-1,4-$ GlcA- $\alpha-1,4-G l c N A c)$ is a receptor of the capsule-specific bacteriophages $\mathrm{K} 5 \mathrm{~A}$ and $\mathrm{K} 1-5$ that both produce a specific lyase acting on the $\alpha-1,4$ bond (Clarke et al. 2000; Thompson et al. 2010).

\section{Conserved structural features of polysaccharide depolymerases}

In spite of the large diversity in enzymatic specificity, depolymerases share strikingly common structural features. Depolymerases described and characterized to date are present in the phage virion within tail fibers or tailspikes on the baseplate, regardless of the phage family they originate from or the host bacterial species they infect (Table 1). One described exception is the depolymerase encoded by Staphylococcus phage vB_SepiS- $\Phi I P L A 7$, which shows $99 \%$ homology with a pre-neck appendage protein (Gutierrez et al. 2015). Generally, depolymerases form elongated homotrimers that appear as protruding cell-puncturing devices on the virion, which aligns well with their biological function. The endosialidase encoded by E. coli siphophage 63D, however, was characterized as a homotetramer (Machida et al. 2000). On the structural level, depolymerases are fibrous proteins with a parallel $\beta$-helix topology composed of parallel $\beta$ strands orthogonal to the long axis (Fig. 1). This protruding shape extends the active site to recognize and bind specific sequences buried within cell surface polysaccharides (Weigele et al. 2003). The P22 tailspike with rhamnosidase activity degrading the LPS O-polysaccharide of Salmonella typhimurium binds its substrate along its entire length (Steinbacher et al. 1996). Therefore, the protruding shape of phage-encoded polysaccharide depolymerases has been proposed to create a long lateral surface for reading the specific polysaccharide sequence, determining the host specificity (Bradley et al. 2001). The complex structure of highly interwoven $\beta$-sheets also determines the high stability of these proteins, since they were found to be resistant to high temperature (possessing relatively high melting point temperature), proteases, and detergents at room temperature. This high stability corresponds to the harsh external conditions these proteins have to withstand in different environments such as the presence of proteases and denaturing conditions (Yan et al. 2014; Majkowska-Skrobek et al. 2016).

\section{Phage-encoded polysaccharide depolymerases in evolution}

Due to the intimate co-evolution between phages and their bacterial hosts, polysaccharide diversity implies corresponding tail fiber and tailspike diversity. The highest level of diversity and mosaicism among phages within the operon of genes encoding structural proteins can be seen in the genes encoding receptor binding proteins (RBPs), reflecting the involvement of intensive vertical and horizontal transfer in the evolution of these proteins (Casjens and Molineux 2012). A 

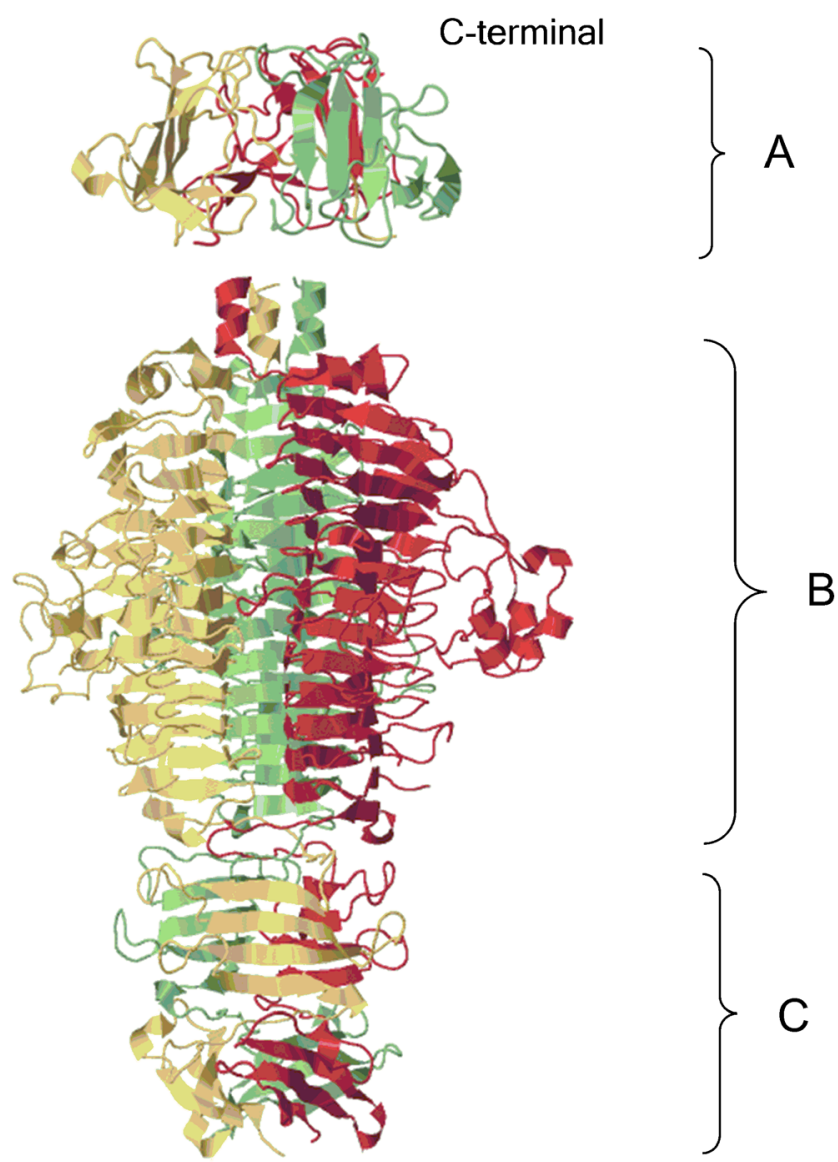

\section{$\mathrm{N}$-terminal}

Fig. 1 Structural architecture of phage tailspike/depolymerase on the base of P22 tailspike (PDB ID 1LKT and 1TYV; JavaScript Protein Viewer). N-terminal dome-like structure domain (a). Central domain for host recognition and enzymatic activity (b). C-terminal domain responsible for protein trimerization or/and receptor recognition (c)

common architecture of RBPs (including polysaccharide depolymerases) consists of three domains (Fig. 1). A small $\mathrm{N}$-terminal domain is responsible for flexible connection of the RBP to the tail structure or to the baseplate. A large central domain forming the elongated homotrimeric structure is the key domain for host recognition and in the case of depolymerases possesses the enzymatic activity. The Cterminal domain seems to be responsible for protein trimerization and mainly works as an intra-molecular chaperone, while others also assign a function of receptor recognition to this domain (Weigele et al. 2003; Cornelissen et al. 2011; Schwarzer et al. 2012; Yan et al. 2014). The N-terminal as well as C-terminal domains of RBPs are conserved among phages belonging to the same group, while the host-specific central domain is highly variable and can be changed to modulate host range or to adapt to a new environment (Stummeyer et al. 2006; Schwarzer et al. 2012). Two different strategies of phages to adapt their RBPs to the polysaccharide receptor while conserving the same motif fold have been described: (1) changing the active site residues by mutation (vertical transfer) and (2) swapping with complete foreign domains specific for a different polysaccharide (horizontal transfer) (Barbirz et al. 2008; Leiman and Molineux 2008).

In the first strategy, many mutations are acceptable in the central domain as far as the stacking interactions between $\beta$ helix rungs remain intact (Leiman and Molineux 2008). This evolution can be observed between the homotrimeric tailspike of phage HK620, specific for E. coli O18A1, and similar tailspikes of phages P22 and Sf6 infecting Salmonella (Barbirz et al. 2008) (Table 1). Specifically, the active site residues involved are located on loops protruding from the $\beta$-helix structure, and thus, mutations therein do not affect the $\beta$-helix conformation. Two phages (HK620 and P22) do bind the polysaccharide between two protruding loops of the same monomer within the homotrimer (i.e., intra-subunit substrate binding), while in the case of phage Sf6, the polysaccharide binding site is located inter-subunit. These differences highlight the phage versatility to adjust the same protein fold to various substrates by mutation in different ways.

The second strategy is based on the exchange of complete tailspike modules to gain different specificity accordingly. This is clearly exemplified by the conserved N-terminal domain among the tailspikes of phages CUS-3, HK620, Sf6, and P22, while the catalytic domain of CUS-3 (i.e., an endosialidase, being specific for the E. coli $\mathrm{K} 1$ antigen) differs completely from the catalytic domain of the three others (Table 1). Moreover, the tailspike of phage K1F comprises the same catalytic domain as CUS-3 but shares the Nterminal domain of the $\mathrm{T} 7$ tail fiber (Stummeyer et al. 2006). These relationships clearly demonstrate evolution through horizontal transfer. A different, more complex configuration of tailspikes are the RBPs of podoviruses K1E, K1-5, and SP6. These viruses produce a specific adapter protein responsible for connection of the host-specific depolymerases to the virion. This adapter protein is equivalent in its function to the N-terminal domain of the tailspikes of CUS-3, HK620, Sf6, and P22 but is a larger, separate protein that provides the attachment site for two tailspikes, each with a different polysaccharide specificity. Tailspikes are interacting with the adapter protein by a short, conserved, N-terminal peptide (Leiman et al. 2007). Specifically, both phages K1E and K1-5 possess tailspikes with endosialidase activity specific for the K1 antigen. Phage K1-5 is equipped additionally with the $\mathrm{K} 5$ lyase enabling recognition of the $\mathrm{K} 5$ antigen (Scholl et al. 2001) (Table 1). Phage K1-5 has thus a dual specificity and can infect both $\mathrm{K} 1$ and $\mathrm{K} 5$ strains. Interestingly, the K1E has a small and probably truncated protein without enzymatic activity as the second tailspike and has therefore a more narrow host spectrum. Clarke et al. (2000) have proposed that phage K1E has evolved from phage K5A by the acquisition of the gene encoding the tailspike with endosialidase activity and the subsequent loss of the $\mathrm{K} 5$ lyase by a $\mathrm{kflA}$ gene truncation. 
Salmonella phage SP6 is morphologically and biologically similar to phages $\mathrm{K} 1 \mathrm{E}$ and $\mathrm{K} 1-5$, but the catalytic domain of the tailspike is homologous to Salmonella phage P22 tailspikes with rhamnosidase activity involved in degradation of the Salmonella O-antigen, explaining the different host spectrum. At the same time, SP6 has a second but still unknown enzymatically active tailspike that broadens the host range to rough and smooth Salmonella strains, in contrary to phage P22 that infects only the smooth type (Scholl et al. 2002, 2004). E. coli bacteriophage $\Phi 92$ isolated in 1983 was reinvestigated by Schwarzer et al. (2012). Apart from the original host $E$. coli $\mathrm{K} 92$, which possesses a polysialic acid capsule, they found that this myovirus is also able to infect non-encapsulated E. coli laboratory strains such as EV5, a capsule defective derivative of a K1 strain; K-12 and B strains; and Salmonella strains (Kwiatkowski et al. 1983; Vimr and Troy 1985; Schwarzer et al. 2012) (Table 1). A cryoEM analysis of the $\Phi 92$ virion showed the presence of a multivalent host adsorption apparatus with at least five different receptor binding proteins being tailspikes or tail fibers. Moreover, the closely related phage PVP-SE1 encodes even six different tail fibers and spikes (Santos et al. 2011; Schwarzer et al. 2012). The best depolymerase-equipped phage is a recently described Klebsiella phage ФK64-1 (Pan et al. 2015, 2017) (Table 1). This giant virus was found to be able to propagate on a broad range of Klebsiella strains, with representatives of up to ten serotypes. ФK64-1 possess 11 genes encoding tail fibers, tailspikes, or lyases. Each expressed protein (S2-4, S1-1, $\mathrm{S} 1-3, \mathrm{~S} 2-2, \mathrm{~S} 2-6, \mathrm{~S} 2-3, \mathrm{~S} 2-5, \mathrm{~S} 1-2, \mathrm{~S} 2-1)$ has activity specific to a different capsular polysaccharide (K1, K11, K21, K25, K30/K69, K35, K64, KN4, and KN5, respectively). Moreover, two proteins (S2-7 and S2-8) were not found active against any capsular serotype known until now (Pan et al. 2017). The electron micrographs of this giant phage revealed similar morphology to phage vB_KleM-RaK2 with broomlike tail fibers and several spike-like structures. Such high variety cannot be achieved in small bacteriophages belonging to Podoviridae family, which have a small tail, but is more likely in larger myoviruses.

\section{Methods for depolymerase activity determination}

Determination of the depolymerizing activity is particularly challenging, as the difficulties to separate CPS/EPS or biofilm matrix from LPS complicate the analysis of polysaccharide degradation. As a consequence, the methods used so far are highly diverse but can generally be subdivided in biological, biochemical, and physical methods that can be either used generally independent of the polysaccharide structure and composition or used for specific substrates. The primary biological way to detect the presence of depolymerases is the application of spots of phages/ enzyme on bacterial lawns and screening for the typical turbid halos (Cornelissen et al. 2011). Spectrophotometric methods allow a more quantitative determination of the depolymerase activity. For the evaluation of biofilm matrix degradation, a standard crystal violet or dimethyl methylene blue (DMMB) dye can be used to quantify biofilm matrix colorimetrically (Cornelissen et al. 2011, 2012; Tote et al. 2008). Spectrometric measurement of reducing sugars allows to determine the EPS/CPS digestion (Yurewicz et al. 1971; Rieger et al. 1975; Hsu et al. 2013). Other methods include examination of periodate oxidation of saccharides by determining the consumption of sodium periodate and the amount of formic acid formed (Kwiatkowski et al. 1983), evaluation of decrease of turbidity of insoluble EPS precipitated by cetylpyridinium chloride (CPC complexes) (Born et al. 2014; Majkowska-Skrobek et al. 2016), or uronic acid release (Glonti et al. 2010). Also, the crude separation of released sugars from polymer was analyzed by TLC chromatography (Glonti et al. 2010). Rheological analyses of alginate gels were done to measure the diffusion rate of phages through exopolysaccharides, as well as viscosity reduction measurements of treated polysaccharides (Thurow et al. 1974; Hanlon et al. 2001; Glonti et al. 2010). A couple of electrophoretic methods were also implemented to analyze depolymerase activity. The non-digested and digested polysaccharides can be compared on polyacrylamide gel electrophoresis (PAGE/SDS PAGE) stained by alcian blue/silver/methylene blue (Clarke et al. 2000; Barbirz et al. 2008; MajkowskaSkrobek et al. 2016). Fluorophore-assisted carbohydrate electrophoresis (FACE) (Chua et al. 1999) and capillary electrophoresis (Baker et al. 2002) are other electrophoretic methods that have been used. For more detailed analysis of the cleavage specificity, the lists of biochemistry techniques were implemented, such as ${ }^{1} \mathrm{H}$ NMR spectroscopy, FABMS, MALDI MS, GC MS, ESIMS, and EIMS (Thurow et al. 1974; Linnerborg et al. 2001). There is also the possibility to measure biofilm thickness by confocal laser scanning microscopy (CLSM) (Cerca et al. 2012), scanning electron microscopy (SEM), or atomic force microscopy (Chatterjee et al. 2014). A fully electric tuning fork resonance frequency measurement system designed by Piasecki et al. (2015) offered an effective mass measurement in a novel approach to evaluate the bacterial biofilm parameters such as mass, viscosity, and density. One of the more sophisticated techniques enabling precise measurement of biofilm matrix degradation is the laser interferometry detecting the small-molecule diffusion rate trough biofilm layer (Danis-Wlodarczyk et al. 2015, 2016).

\section{Applications of polysaccharide depolymerases}

The unique ability of phage-derived depolymerases to specifically recognize and degrade CPS, EPS, and the O-antigen offers an attractive and promising tool for controlling pathogenic bacteria and other applications, including clinical diagnostics and biochemical analyses. Although most of these proteins do not seem to possess bactericidal activity as described for VALs and endolysins, they should be considered in therapy for their 
antivirulent potential (Majkowska-Skrobek et al. 2016). The loss or modification of bacterial surface structures that are used by many pathogens to promote virulence, host colonization, and biofilm formation makes bacteria less pathogenic and/or sensitizes them to either some antimicrobials or host defenses such as phagocytosis by macrophages and the bactericidal action of serum (Mushtaq et al. 2004, 2005; Zelmer et al. 2010; Bansal et al. 2014; Pan et al. 2015). Therapeutic efficacy of recombinant depolymerases that only modify the phenotype of the bacterial cells without affecting their viability and growth rate has been confirmed in animal models (Mushtaq et al. 2004; Waseh et al. 2010; Pan et al. 2015; Majkowska-Skrobek et al. 2016). When phage K1E endosialidase (endoNE) is administered intraperitoneally to neonatal rats infected with neuroinvasive $E$. coli $\mathrm{K} 1$ strains, a significant reduction of mortality due to bacteremia and the life-threatening systemic infection was observed (Mushtaq et al. 2004, 2005; Zelmer et al. 2010). In another study, the oral administration of Salmonella-specific endorhamnosidase from P22 phage (P22sTsp) to chickens prevented the pathogen's colonization of the gut and its penetration into internal organs (Waseh et al. 2010). An interesting approach is the idea of alginate lyase application as an antibiofilm agent in combating Pseudomonas aeruginosa biofilm in the airways of cystic fibrosis patients (Glonti et al. 2010). Degradation of alginate, the exopolysaccharide produced by mucoid $P$. aeruginosa strains, can remove a barrier that protects bacterial cells from macrophages in the lungs, can perturb bacterial growth in biofilms, and decreases the viscosity of sputum (Hanlon et al. 2001; Glonti et al. 2010). Depolymerase-mediated biocontrol of pathogens has also been successfully attempted in a pathogen-plant system. Effective enzyme application has been observed in transgenic pears and apples that express the EPS-degrading enzyme from $\Phi$ Ealh phage, conferring resistance to fire blight caused by Erwinia amylovora (Malnoy et al. 2005; Flachowsky et al. 2008). An important challenge is the creation of depolymerases with lytic activity. A study carried out by Scholl et al. (2009) revealed that a recombinant fusion protein between the endorhamnosidase-active tailspike protein from E. coli O157specific phage $\Phi \mathrm{V} 10$ and a R-type pyocin is able to lyse E. coli $\mathrm{O} 157: \mathrm{H} 7$ strains and can be applied to eliminate the pathogen from food.

Phages able to express several depolymerases can also be constructed by synthetic biology ( $\mathrm{Lu}$ and Collins 2007; Azeredo and Sutherland 2008). Potentially, in comparison to phages currently used in therapy, these genetically modified phages with a broader range of activities would be more effective or even target other serotypes. Depolymerases could also be applied in combination with conventional antimicrobials against multidrug-resistant pathogens, notably those living in biofilm communities. The synergistic action of either phages producing depolymerase or recombinant depolymerase with conventional chemical agents, including antibiotics and disinfectants, have already been shown to suppress Klebsiella infections (Verma et al. 2009, 2010; Bansal et al. 2014; Chai et al. 2014). Moreover, the ability of phages to express not only their own but also other bacterial enzymes indicates their potential to specifically target pathogens possessing for example chondroitin capsules (Cress et al. 2014). Besides combating bacterial infections, depolymerases can be used as an alternative to antiserum for the typing of bacterial strains and the detection of polysaccharides in immunohistological studies. The first test of this concept was initially realized with Klebsiella strains. Owing to the high specificity of depolymerases, it was suggested that enzymebased capsular typing may be more useful than whole phage typing (Hsu et al. 2013; Lin et al. 2014). The analogous approach has been successfully applied to develop an endosialidase-based detection reagent for identification of polysialic acid-containing bacteria as well as eukaryotic cells (Jakobsson et al. 2015). As a detection tool, these enzymes are used in a catalytically inactive form, capable to recognize and bind the substrate, but without its degradation. Their potential advantages that give them the supremacy over antibodies are (i) the production based on recombinant technology without the use of animals, (ii) the lack of cross-reactivity with cell surface proteins, and (iii) the lack of toxicity. It is also worth noting that endosialidases, besides therapeutic and diagnostic significance, are also of interest as tool to degrade artificial polysialic acid-based hydrogels and other derivatives used as a scaffold biomaterial in neurobiology (Berski et al. 2008).

\section{Virion-associated lysins}

VALs are generally linked to a component of the virion and therefore are also known as VAPGHs (Rodríguez-Rubio et al. 2013a), tail-associated muralytic enzymes (TAMEs) (Paul et al. 2011), and structural lysins or exolysins (Oliveira et al. 2013). However, all these names are confusing. First of all, some VALs are in fact lytic transglycosylases, which are not hydrolases. Secondly, the phage tail is the most common attachment site for VALs, but not the only one. VAL can also be anchored to the phage neck, baseplate, or can be embedded in the viral membrane. Thirdly, some VALs do not serve as structural elements but are connected to the genomic phage DNA or occur as free form enclosed in the capsid (Table 2). Finally, exolysins are generally associated with enzymes secreted by a bacterium to kill competing bacteria. For these reasons, virion-associated lysin is the most appropriate name and is used in this review.

\section{Enzymatic mechanism of action and specificity of VALs}

Based on the type of the chemical bond that is cleaved, the specificity of VALs is classified into three categories: (i) glycosidases, further subdivided into lysozymes, glucosaminidases, and lytic transglycosylases, cleaving one of the two glycosidic bonds in the glycan chain; (ii) amidases cutting the amide bond 


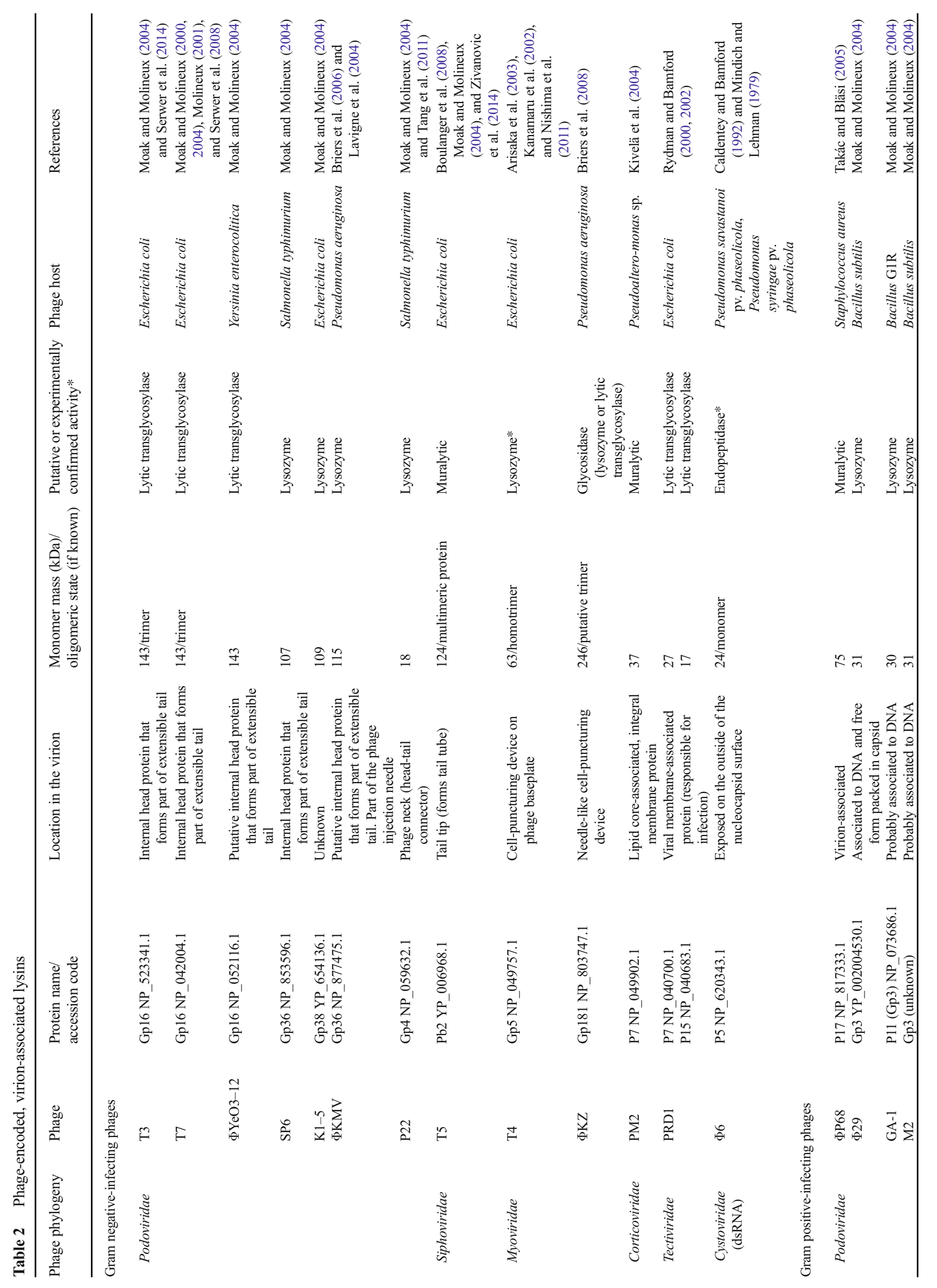


between the lactyl group of $\mathrm{N}$-acetylmuramic acid and L-alanine of the stem peptide; and (iii) endopeptidases cleaving within the stem peptide or the cross-link (Young 1992). The vast majority of described VALs, including the best studied examples from coliphages T4 (Gp5-lysozyme) and T7 (Gp16-lytic transglycosylase) (Yap and Rossmann 2014; Moak and Molineux 2000) are glycosidases (Table 2), and technically, only those enzymes are carbohydrate active enzymes. Lysozymes and lytic transglycosylases cleave the same $\beta$-1,4-glycosidic linkage between $\mathrm{N}$-acetylmuramic acid and N-acetyl-D-glucosamine. However, lytic transglycosylases are not hydrolases like lysozymes as they do not use a water molecule during cleavage but instead catalyze the concomitant formation of a 1,6anydromuramoyl product (Scheurwater et al. 2008). Endopeptidase activity is generally attributed to VALs of Gram-positive-specific phages such as ORF56, Gp44, $\mathrm{Tal}(2009)$, and Tal(901-1) and CwlP encoded by phages K, $\Phi 11$, Tuc2009, TP901-1, and SP- $\beta$, respectively (Sudiarta et al. 2010; Paul et al. 2011; Stockdale et al. 2013) (Table 2). Only one VAL originating from a Gram-negative-infecting phage, specifically Gp5 of Pseudomonas phage $\Phi 6$ (dsRNA, Cystoviridae), has been demonstrated to possess endopeptidase activity (Caldentey and Bamford 1992). VALs with amidase activity include Gp61, HydH5, and Gp49 of Staphylococcusspecific Siphoviridae $\Phi$ MR11, IPLA88, and $\Phi 11$ (Rashel et al. 2008; Rodríguez et al. 2011) (Table 2).

\section{Various architectures of VALs}

In terms of structure, VALs are highly diverse enzymes. Differences relate to the number of domains and their organization, molecular weight, and oligomeric state. The structure of VALs is modular and reminiscent of the structure of many polysaccharide depolymerases. It consists of a domain that binds to the virion and one or two lytic domains responsible for PG degradation. An additional domain, responsible for cell wall binding, was found in P17 VAL of staphylococcal phage P68 (Takác and Bläsi 2005). The majority of VALs possess a single lytic domain. Only five VALs with two different lytic domains have been reported for Staphylococcus phages (Table 2), which are CwlP of prophage SP- $\beta$ with lysozyme and endopeptidase domains (Sudiarta et al. 2010), Gp44 of phage $\Phi 11$ with endopeptidase and SGNH hydrolase domains (Li et al. 2016), Gp61 of phage $\Phi M R 11$ (Rashel et al. 2008), HydH5 of phage $\Phi I P L A 88$ (Rodríguez et al. 2011; Rodríguez-Rubio et al. 2012, 2013b), and Gp49 of phage $\Phi 11$ (Rodríguez-Rubio et al. 2013c; Li et al. 2016), all with lysozyme and amidase activities. Interestingly, all VALs with two lytic domains are encoded by phages specific for Grampositive bacteria, which may be related with the thick cell wall of Gram-positive cells (Table 2). The order of VAL domains is also variable. Lytic active domains can be located at the Nterminus (e.g., P17 of phage P68, Gp3 of phage $\Phi 29$ ) (Moak 
and Molineux 2004; Takác and Bläsi 2005), at the C-terminus (e.g., Gp36 of phage $\Phi \mathrm{KMV}$ and $\mathrm{Pb} 2$ of phage T5) (Lavigne et al. 2004; Boulanger et al. 2008), or at both termini of the protein (e.g., Gp44 and Gp49 of phage $\Phi 11$ ) (Li et al. 2016). Equally large diversity is observed for the molecular weight of VALs within the range of $37-252 \mathrm{kDa}$, with the smallest being the internal membrane VAL P7 of phage PM2 (Kivelä et al. 2004) and the largest being CwlP of prophage SP- $\beta$ (Sudiarta et al. 2010), respectively. The oligomeric state has only been characterized for a few VALs. They can be present as monomers like the viral membrane-associated Gp5 of phage $\Phi 6$ (Caldentey and Bamford 1992) but also as a dodecamer like Gp4 found in neck of phage P22 (Tang et al. 2011). However, a trimeric state as found in Gp5, component of the hub of the T4 phage baseplate (Kanamaru et al. 2002), Tal(2009) and Tal(901-1) forming the tail tips of phages Tuc2009 and TP901-1, respectively (Stockdale et al. 2013), is the most frequently described oligomeric state. It is also worth to mention that E. coli phage PDR1 (Tectiviridae) and Staphylococcus phage $\Phi 11$ (Siphoviridae) are the only known examples of bacterial viruses equipped with two different VALs (Table 2).

\section{Location of VALs in the virion}

VALs appear in various parts of the virion. In the case of Tectiviridae, membrane-containing coliphages like PRD1 (proteins P7 and P15) and $\Phi 6$ (Gp5) VALs are associated with the viral membrane and exposed on the outside of the nucleocapsid surface (Caldentey and Bamford 1992; Rydman and Bamford 2000, 2002). The phage tail is the most common location of VALs encoded by Caudovirales, wherein the tail tip is the most typical location of VALs from Siphoviridae attacking Gram positives (Table 2). Another location is the baseplate where VAL oligomers form a cell-puncturing device. Baseplate location is characteristic for Gp5 of T4 coliphage (Kanamaru et al. 2002) and gp181 of Pseudomonas phage $\Phi \mathrm{KZ}$ (Briers et al. 2008; Fokine et al. 2008). The Gp4 of the Salmonella-specific phage P22 is the only VAL described so far that is located at the phage neck (Tang et al. 2011). The Gp16 encoded by phages T7, T3, and øYeO3-12 and Gp36 of phage SP6 are internal head proteins that form part of an extensible tail, which is characteristic for most Gram-negative-specific Podoviridae (Struthers-Schlinke et al. 2000; Moak and Molineux 2004; Serwer et al. 2008, 2014). Also, Gp3 of phage $\Phi 29$ and probably Gp3 of the similar phages GA-1 and M2 as well are located in the phage head but are linked to the genomic DNA. VALs of these Podoviridae infecting Gram-positive Bacillus sp. are ejected from the virion prior the DNA, allowing efficient infection (Moak and Molineux 2004). Moreover, it was demonstrated that a small portion of the free form of Gp3 (not attached to DNA) is enclosed inside the capsid of phage $\Phi 29$ and may move down to the tail tip, digesting the peptidoglycan together with the portion of Gp3 that is covalently bound to DNA (Moak and Molineux 2004).

\section{Methods for activity determination of VALs}

As for depolymerases, there is no standard procedure for the evaluation of the enzymatic activity of VALs. However, the variability in peptidoglycan composition is lower than the one of EPS, CPS, and O-polysaccharide, resulting in some more common practices for which either purified substrates are used (PG, sugar chains, peptides) or whole cells. These cells can be either a living or a dead, autoclaved cell suspension. In case of Gram-negative cells, the outer membrane has to be removed first to make the PG accessible. Outer membrane permeabilization is hereby achieved by chloroform vapor that dissolves the lipid inner and outer membranes. The lytic activity of most described VALs has been demonstrated on purified PG using in-gel activity staining (zymography) or by spectrophotometry using whole cells (Caldentey and Bamford 1992; Kaberdin and McDowall 2003; Moak and Molineux 2004; Kivelä et al. 2004; Lavigne et al. 2004; Sudiarta et al. 2010; Briers et al. 2006, 2008; Rodríguez et al. 2011; Stockdale et al. 2013; Rodríguez-Rubio et al. 2012). Both methods imply the analysis of the reduction in turbidity of the substrate, either as transparent bands in turbid gels (zymography) or by spectrophotometry measuring the optical density. The spectrophotometric approach is the most accurate to quantify the enzymatic (U/ml) or specific (U/mg) activity. It is also commonly used for endolysin testing and relies on determination of the rate of reduction of the optical density of a substrate suspension at $600 \mathrm{~nm}$ upon addition of a given amount of enzyme (expressed as $\Delta \mathrm{OD}_{600} / \mu \mathrm{g} \min$ ) (Donovan et al. 2006; Donovan and Foster-Frey 2008; Becker et al. 2009; Rodríguez-Rubio et al. 2012). The general limitation of this method is the high "day-to-day" variability in the results (Donovan and Foster-Frey 2008). A standardized approach for enzymatic activity determination of PG-degrading endolysins against Gram-negative strains has been proposed by Briers and co-workers (Briers et al. 2007a) and relies on the determination of the linear region of the turbidity drop. Enzymatic activity is expressed in U, often corresponding to a linear descent in $\mathrm{OD}_{600}$ of 0.001 per min (Cheng et al. 1994). This method has been used for determination of enzymatic activity of VALs of phages $\Phi$ KMV (Lavigne et al. 2004) and $\Phi \mathrm{KZ}$ (Briers et al. 2008). The cleavage specificity of phages lysins is only rarely experimentally examined and is often based on in silico homology and therefore biased by historic misannotations. However, in those few experimentally validated cases, liquid chromatography-mass spectrometry is the most common method (Caldentey and Bamford 1992; Sudiarta et al. 2010; Stockdale et al. 2013; Rodríguez-Rubio et al. 2016; Maciejewska et al. 2017). 


\section{Use of lysins as antibacterial proteins}

VALs possess properties that make them potential weapons to prevent and combat bacterial pathogens. Indeed, purified VALs kill Gram-positive cells when they are added exogenously as the PG is directly accessible and its breakdown results in osmotic lysis and immediate cell death. Similar to the use of endolysins for the same goal, VALs are featured by (i) high specificity, targeting only a subset of pathogens; (ii) desirable mode of action on unique and highly conserved bonds in PG, reducing the risk on fast emergence and spread of resistance; (iii) lytic and antibacterial activities regardless of the presence of antibiotic resistance mechanisms; and (iv) additional useful features like thermostability, high ionic strength tolerance, and synergistic activity with antibiotics or endolysins. The antibacterial activity of VALs against Grampositive bacteria mainly focused on Staphylococcus aureus. The P17 VAL was shown to have a spectrum activity against most of $S$. aureus clinical strains, including isolates resistant to phage P68, the producer of P17 (Takác and Bläsi 2005). Antistaphylococcal activity was also demonstrated for both lytic domains of Gp61 of phage $\Phi \mathrm{MR} 11$, causing lysis of approximately $80 \%$ of $S$. aureus cells within $30 \mathrm{~min}$ (Rashel et al. 2008). Other VALs lethal to $S$. aureus are ORF56 of phage K (Paul et al. 2011) and HydH5 of phage SIPLA88, which were shown to lyse $S$. aureus (including methicillinresistant $S$. aureus (MRSA)) and S. epidermidis. Moreover, HydH5 is thermostable up to $100{ }^{\circ} \mathrm{C}$ for 5 min and acts synergistically with endolysin LysH5 (Rodríguez et al. 2011; Rodríguez-Rubio et al. 2012). Regarding Gram-negative pathogens, VALs have been demonstrated to lyse the peptidoglycan of outer membrane-permeabilized cells. Gp36 of phage $\Phi \mathrm{KMV}$ and Gp181 of phage $\Phi \mathrm{KZ}$ showed lytic activity against $P$. aeruginosa with a specific activity of $4800 \mathrm{U} / \mathrm{mg}$ (similar to commercial hen egg white lysozyme) and $60,000 \mathrm{U} / \mathrm{mg}$, respectively (Lavigne et al. 2004; Briers et al. 2006, 2008). Furthermore, Gp36 possesses a highly thermostable, C-terminal lysozyme domain retaining activity after treatments of at $95^{\circ} \mathrm{C}$, whereas the $\mathrm{Gp} 181$ tolerates high ionic stress (>320 mM) (Briers et al. 2008). Gp5 of Pseudomonas phage $\Phi 6$ is lytic in vitro against several outer membranepermeabilized, Gram-negative species (Pseudomonas phaseolicola, P. aeruginosa, P. fluorescens, P. putida, E. coli, S. typhimurium, and Proteus vulgaris) (Caldentey and Bamford 1992). In spite of a natural exogenously acting function, lysins can generally not penetrate the outer membrane when not associated with the virion. Therefore, recombinant lysins can only kill intact Gram-negative bacteria in presence of outer membrane permeabilizers such as EDTA. Genetic modification with outer membrane-permeabilizing peptides as has been described for endolysins in the development of artilysins (Briers et al. 2014; Gerstmans et al. 2016) can be an option. In context of the improvement of the potential of VALs as antibacterials, different chimeric proteins comprising one or more domains of lysins have been constructed and characterized. P16-17 comprising the Nterminal endopeptidase domain of the endolysin (P16) and the C-terminal cell wall binding domain of the VAL (P17) of Staphylococcus phage 68 shows a high and specific antibacterial activity against $S$. aureus strains. P16-17 acts synergistically with gentamicin and increases bacterial sensitivity towards this drug (Manoharadas et al. 2009). Protein P128, a chimera of the $\mathrm{N}$-terminal endopeptidase of the structural lysin from staphylococcal $\mathrm{K}$ phage and the cell wall-binding SH3 of lysostaphin, was demonstrated to possess strong antistaphylococcal activity and was successfully used in decolonization of rat nares from staphylococcal infection, reducing the bacterial load by two orders of magnitude after treatment. Moreover, P128-resistant mutants were shown to lose the $\beta$-lactam drug resistance phenotype and become hypersensitive to $\beta$-lactams (Paul et al. 2011; Saravanan et al. 2013; Sundarrajan et al. 2014). Two other chimeric proteins, i.e., HydH5Lyso and HydH5SH3b, were prepared based on the HydH5 from $S$. aureus-specific phage IIPLA88. The HydH5Lyso (a fusion of HydH5 with lysostaphin) and HydH5SH3b (fusion of HydH5 with lysostaphin binding domain SH3b) were able to lyse MRSA and S. epidermidis cells with higher activity than each of the enzymes separately. Both chimeric proteins have proven their usefulness as effective milk biopreservatives (Rodríguez-Rubio et al. 2012). Another chimeric protein composed of the endopeptidase domain of the VAL and the cell wall binding domain of the endolysin of Enterococcus faecalis phage F170/08 is the EC300 protein. The muralytic activity of EC300 showed enhanced activity over the original lysins against clinical, multidrug resistant $E$. faecalis strains (Proença et al. 2015).

In conclusion, phages have evolved elaborate, virionassociated carbohydrate active enzymes that accommodate the existing diversity in carbohydrate barriers presented to phages during infection. This intimate co-evolution with a high evolutionary rate has provided us with a highly versatile tool kit of specific proteins to either kill, sensitize, or detect bacteria.

Acknowledgements This project was financed by National Science Centre, Poland, granted based on decision nos. DEC-2015/19/N/NZ1/ 00014 and DEC-2012/07/N/NZ9/01780. Agnieszka Latka has received a doctoral scholarship of the "Bijzonder Onderzoeksfonds" of Ghent University (BOF16/FJD/007).

Compliance with ethical standards This article does not contain any studies with human participants or animals performed by any of the authors.

Conflict of interest The authors declare that they have no competing interests. 
Open Access This article is distributed under the terms of the Creative Commons Attribution 4.0 International License (http:// creativecommons.org/licenses/by/4.0/), which permits unrestricted use, distribution, and reproduction in any medium, provided you give appropriate credit to the original author(s) and the source, provide a link to the Creative Commons license, and indicate if changes were made.

\section{References}

Abedon ST (2012) Spatial vulnerability: bacterial arrangements, microcolonies, and biofilms as responses to low rather than high phage densities. Viruses 4:663-687. doi:10.3390/v4050663

Adams MH, Park BH (1956) An enzyme produced by a phage-host cell system. II. The properties of the polysaccharide depolymerase. Virology 2(6):719-736. doi:10.1016/0042-6822(56)90054-x

Arisaka F, Kanamaru S, Leiman P, Rossmann MG (2003) The tail lysozyme complex of bacteriophage T4. Int J Biochem Cell Biol 35:16-21

Azeredo J, Sutherland IW (2008) The use of phages for the removal of infectious biofilms. Curr Pharm Biotechnol 4:261-266

Baker JR, Dong S, Pritchard DG (2002) The hyaluronan lyase of Streptococcus pyogenes bacteriophage H4489A. Biochem J 365(Pt 1):317-322. doi:10.1042/bj20020149

Bansal S, Harjai K, Chhibber S (2014) Depolymerase improves gentamicin efficacy during Klebsiella pneumoniae induced murine infection. BMC Infect Dis 14:456. doi:10.1186/1471-2334-14-456

Barbirz S, Muller JJ, Uetrecht C, Clark AJ, Heinemann U, Seckler R (2008) Crystal structure of Escherichia coli phage HK620 tailspike: podoviral tailspike endoglycosidase modules are evolutionarily related. Mol Microbiol 69(2):303-316. doi:10.1111/j.1365-2958.2008.06311.x

Baxa U, Steinbacher S, Miller S, Weintraub A, Huber R, Seckler R (1996) Interactions of phage P22 tails with their cellular receptor, Salmonella O-antigen polysaccharide. Biophys J 71(4):2040-2048

Becker SC, Dong S, Baker JR, Foster-Frey J, Pritchard DG, Donovan DM (2009) LysK CHAP endopeptidase domain is required for lysis of live staphylococcal cells. FEMS Microbiol Lett 294:52-60. doi: 10.1111/j.1574-6968.2009.01541.x

Berski S, van Bergeijk J, Schwarzer D, Stark Y, Kasper C, Scheper T, Grothe C, Gerardy-Schahn R, Kirschning A, Dräger G (2008) Synthesis and biological evaluation of a polysialic acid-based hydrogel as enzymatically degradable scaffold material for tissue engineering. Biomacromolecules 9:2353-2359. doi:10.1021/bm800327s

Bertozzi Silva J, Storms Z, Sauvageau D (2016) Host receptors for bacteriophage adsorption. FEMS Microbiol Lett 363(4):fnw002. doi: 10.1093/femsle/fnw002

Bessler W, Freund-Molbert E, Knufermann H, Rudolph C, Thurow H, Stirm S (1973) Bacteriophage-induced depolymerase active on Klebsiella K11 capsular polysaccharide. Virology 56(1):134-151. doi:10.1016/0042-6822(73)90293-6

Born Y, Fieseler L, Klumpp J, Eugster MR, Zurfluh K, Duffy B, Loessner MJ (2014) The tail-associated depolymerase of Erwinia amylovora phage L1 mediates host cell adsorption and enzymatic capsule removal, which can enhance infection by other phage. Environ Microbiol 16:2168-2180. doi:10.1111/1462-2920.12212

Boulanger P, Jacquot P, Plançon L, Chami M, Engel A, Parquet C, Herbeuval C, Letellier L (2008) Phage T5 straight tail fiber is a multifunctional protein acting as a tape measure and carrying fusogenic and muralytic activities. J Biol Chem 283:13556-13564. doi:10.1074/jbc.M800052200

Bradley P, Cowen L, Menke M, King J, Berger B (2001) BETAWRAP: successful prediction of parallel beta-helices from primary sequence reveals an association with many microbial pathogens. Proc Natl Acad Sci U S A 98(26):14819-14824. doi:10.1073/pnas.251267298
Briers Y, Lavigne R, Plessers P, Hertveldt K, Hanssens I, Engelborghs Y, Volckaert G (2006) Stability analysis of the bacteriophage phiKMV lysin gp36C and its putative role during infection. Cell Mol Life Sci 63:1899-1905. doi:10.1007/s00018-006-6183-7

Briers Y, Lavigne R, Volckaert G, Hertveldt K (2007a) A standardized approach for accurate quantification of murein hydrolase activity in high-throughput assays. J Biochem Biophys Methods 70:531-533. doi:10.1016/j.jbbm.2006.10.009

Briers Y, Miroshnikov K, Chertkov O, Nekrasov A, Mesyanzhinov V, Volckaert G, Lavigne R (2008) The structural peptidoglycan hydrolase gp181 of bacteriophage phiKZ. Biochem Biophys Res Commun 374:747-751. doi:10.1016/j.bbrc.2008.07.102

Briers Y, Volckaert G, Cornelissen A, Lagaert S, Michiels CW, Hertveldt K, Lavigne R (2007b) Muralytic activity and modular structure of the endolysins of Pseudomonas aeruginosa bacteriophages phiKZ and EL. Mol Microbiol 65:1334-1344. doi:10.1111/j.1365-2958.2007.05870.x

Briers Y, Walmagh M, Van Puyenbroeck V, Cornelissen A, Cenens W, Aertsen A, Oliveira H, Azeredo J, Verween G, Pirnay J-P, Miller S, Volckaert G, Lavigne R (2014) Engineered endolysin-based "artilysins" to combat multidrug-resistant gram negative pathogens. MBio 5:e01379-e01314. doi:10.1128/mBio.01379-14

Caldentey J, Bamford DH (1992) The lytic enzyme of the Pseudomonas phage phi 6. Purification and biochemical characterization. Biochim Biophys Acta 1159:44-50. doi:10.1016/0167-4838(92)90073-M

Casjens SR, Leavitt JC, Hatfull GF, Hendrix RW (2014) Genome sequence of Salmonella phage 9NA. Genome Announc 2(4): e00531-e00514. doi:10.1128/genomeA.00531-14

Casjens SR, Molineux IJ (2012) Short noncontractile tail machines: adsorption and DNA delivery by podoviruses. Adv Exp Med Biol 726: 143-179. doi:10.1007/978-1-4614-0980-9 7

Cerca N, Gomes F, Pereira S, Teixeira P, Oliveira R (2012) Confocal laser scanning microscopy analysis of $S$. epidermidis biofilms exposed to farnesol, vancomycin and rifampicin. BMC Res Notes 5:244. doi: 10.1186/1756-0500-5-244

Chang JT, Schmid MF, Haase-Pettingell C, Weigele PR, King JA, Chiu W (2010) Visualizing the structural changes of bacteriophage Epsilon15 and its Salmonella host during infection. J Mol Biol 402(4):731-740. doi:10.1016/j.jmb.2010.07.058

Chai Z, Wang J, Tao S, Mou H (2014) Application of bacteriophageborne enzyme combined with chlorine dioxide on controlling bacterial biofilm. LWT Food Sci Technol 59:1159-1165. doi:10.1016/j. lwt.2014.06.033

Chatterjee S, Biswas N, Datta A, Dey R, Maiti P (2014) Atomic force microscopy in biofilm study. Microscopy 63(4):269-278. doi:10. 1093/jmicro/dfu013

Cheng X, Zhang X, Pflugrath JW, Studier FW (1994) The structure of bacteriophage $\mathrm{T} 7$ lysozyme, a zinc amidaseand an inhibitor of $\mathrm{T} 7$ RNA polymerase. Proc Natl Acad Sci U S A 91:4034-4038

Chua JE, Manning PA, Morona R (1999) The Shigella flexneri bacteriophage Sf6 tailspike protein (TSP)/endorhamnosidase is related to the bacteriophage P22 TSP and has a motif common to exo- and endoglycanases, and C-5 epimerases. Microbiology 145(Pt 7): $1649-1659$

Clarke BR, Esumeh F, Roberts IS (2000) Cloning, expression, and purification of the K5 capsular polysaccharide lyase (KflA) from coliphage K5A: evidence for two distinct K5 lyase enzymes. J Bacteriol 182(13):3761-3766. doi:10.1128/jb.182.13.3761-3766.2000

Corbett D, Roberts IS (2008) Capsular polysaccharides in Escherichia coli. Adv Appl Microbiol 65:1-26. doi:10.1016/s0065-2164(08)00601-1

Cornelissen A, Ceyssens PJ, Krylov VN, Noben JP, Volckaert G, Lavigne R (2012) Identification of EPS-degrading activity within the tail spikes of the novel Pseudomonas putida phage AF. Virology 434(2):251-256. doi:10.1016/j.virol.2012.09.030

Cornelissen A, Ceyssens PJ, T'Syen J, Van Praet H, Noben JP, Shaburova OV, Krylov VN, Volckaert G, Lavigne R (2011) The T7-related 
Pseudomonas putida phage phi 15 displays virion-associated biofilm degradation properties. PLoS One 6(4):e18597. doi:10.1371/ journal.pone.0018597

Cress BF, Englaender JA, He W, Kasper D, Linhardt RJ, Koffas MA (2014) Masquerading microbial pathogens: capsular polysaccharides mimic host-tissue molecules. FEMS Microbiol Rev 38:660 697. doi:10.1111/1574-6976.12056

Danis-Wlodarczyk K, Olszak T, Arabski M, Wasik S, Majkowska-Skrobek G, Augustyniak D, Gula G, Briers Y, Jang HB, Vandenheuvel D, Duda KA, Lavigne R, Drulis-Kawa Z (2015) Characterization of the newly isolated lytic bacteriophages KTN6 and KT28 and their efficacy against Pseudomonas aeruginosa biofilm. PLoS One 10(5):e0127603. doi:10. 1371/journal.pone.0127603

Danis-Wlodarczyk K, Vandenheuvel D, Jang HB, Briers Y, Olszak T, Arabski M, Wasik S, Drabik M, Higgins G, Tyrrell J, Harvey BJ, Noben JP, Lavigne R, Drulis-Kawa Z (2016) A proposed integrated approach for the preclinical evaluation of phage therapy in Pseudomonas infections. Sci Rep 6:28115. doi:10.1038/srep28115

Davidson IW, Lawson CJ, Sutherland IW (1977) Alginate lyase from Azotobacter vinelandii phage. J Gen Microbiol 98(1):223-229

Davies G, Henrissat B (1995) Structures and mechanisms of glycosyl hydrolases. Structure 3(9):853-859. doi:10.1016/s0969-2126(01)00220-9

Donovan DM, Dong S, Garrett W, Rousseau GM, Moineau S, Pritchard DG (2006) Peptidoglycan hydrolase fusions maintain their parental specificities. Appl Environ Microbiol 72:2988-2996. doi:10.1128/ AEM.72.4.2988-2996.2006

Donovan DM, Foster-Frey J (2008) LambdaSa2 prophage endolysin requires Cpl-7-binding domains and amidase-5 domain for antimicrobial lysis of streptococci. FEMS Microbiol Lett 287:22-33. doi:10. 1111/j.1574-6968.2008.01287.x

Drulis-Kawa Z, Majkowska-Skrobek G, Maciejewska B, Delattre AS, Lavigne R (2012) Learning from bacteriophages — advantages and limitations of phage and phage-encoded protein applications. Curr Protein Pept Sci 13(8):699-722

Drulis-Kawa Z, Majkowska-Skrobek G, Maciejewska B (2015) Bacteriophages and phage-derived proteins-application approaches. Curr Med Chem 22:1757-1773. doi:10.2174/ 0929867322666150209152851

Ferretti JJ, McShan WM, Ajdic D, Savic DJ, Savic G, Lyon K, Primeaux C, Sezate S, Suvorov AN, Kenton S, Lai HS, Lin SP, Qian Y, Jia HG, Najar FZ, Ren Q, Zhu H, Song L, White J, Yuan X, Clifton SW, Roe BA, McLaughlin R (2001) Complete genome sequence of an M1 strain of Streptococcus pyogenes. Proc Natl Acad Sci U S A 98(8):4658-4663. doi:10.1073/pnas.071559398

Flachowsky H, Richter K, Kim WS, Geider K, Hanke MV (2008) Transgenic expression of a viral EPS-depolymerase is potentially useful to induce fire blight resistance in apple. Annu Appl Biol 153:345-355. doi:10.1111/j.1744-7348.2008.00264.x

Fokine A, Miroshnikov KA, Shneider MM, Mesyanzhinov VV, Rossmann MG (2008) Structure of the bacteriophage phi KZ lytic transglycosylase gp144. J Biol Chem 283:7242-7250. doi:10.1074/ jbc.M709398200

Freiberg A, Morona R, Van den Bosch L, Jung C, Behlke J, Carlin N, Seckler R, Baxa U (2003) The tailspike protein of Shigella phage Sf6. A structural homolog of Salmonella phage P22 tailspike protein without sequence similarity in the beta-helix domain. J Biol Chem 278(3):1542-1548. doi:10.1074/jbc.M205294200

Gerardy-Schahn R, Bethe A, Brennecke T, Muhlenhoff M, Eckhardt M, Ziesing S, Lottspeich F, Frosch M (1995) Molecular cloning and functional expression of bacteriophage PK1E encoded endoneuraminidase endo NE. Mol Microbiol 16(3):441-450

Gerstmans H, Rodríguez-Rubio L, Lavigne R, Briers Y (2016) From endolysins to Artilysin®s: novel enzyme-based approaches to kill drug-resistant bacteria. Biochem Soc Trans 44:123-128. doi:10. 1042/BST20150192
Glonti T, Chanishvili N, Taylor PW (2010) Bacteriophage-derived enzyme that depolymerizes the alginic acid capsule associated with cystic fibrosis isolates of Pseudomonas aeruginosa. J Appl Microbiol 108:695-702. doi:10.1111/j.1365-2672.2009.04469.x

Guichard JA, Middleton PC, McConnell MR (2013) Genetic analysis of structural proteins in the adsorption apparatus of bacteriophage Epsilon15. World J Virol 2(4):152-159. doi:10.5501/wjv.v2.i4.152

Gutierrez D, Briers Y, Rodriguez-Rubio L, Martinez B, Rodriguez A, Lavigne R, Garcia P (2015) Role of the pre-neck appendage protein (Dpo7) from phage vB_SepiS-philPLA7 as an anti-biofilm agent in Staphylococcal species. Front Microbiol 6:1315. doi:10.3389/ fmicb.2015.01315

Hallenbeck PC, Vimr ER, Yu F, Bassler B, Troy FA (1987) Purification and properties of a bacteriophage-induced endo-Nacetylneuraminidase specific for poly-alpha-2,8-sialosyl carbohydrate units. J Biol Chem 262(8):3553-3561

Hanlon GW, Denyer SP, Olliff CJ, Ibrahim LJ (2001) Reduction in exopolysaccharide viscosity as an aid to bacteriophage penetration through Pseudomonas aeruginosa biofilms. Appl Environ Microbiol 67(6):2746-2753. doi:10.1128/aem.67.6.2746-2753.2001

Hoyles L, Murphy J, Neve H, Heller KJ, Turton JF, Mahony J, Sanderson JD, Hudspith B, Gibson GR, McCartney AL, van Sinderen D (2015) Klebsiella pneumoniae subsp. pneumoniae bacteriophage combination from the caecal effluent of a healthy woman. Peerj 3:e1061. doi: 10.7717 peerj. 1061

Hsu CR, Lin TL, Pan YJ, Hsieh PF, Wang JT (2013) Isolation of a bacteriophage specific for a new capsular type of Klebsiella pneumoniae and characterization of its polysaccharide depolymerase. PLoS One 8(8): e70092. doi:10.1371/journal.pone.0070092

Hynes WL, Hancock L, Ferretti JJ (1995) Analysis of a second bacteriophage hyaluronidase gene from Streptococcus pyogenes: evidence for a third hyaluronidase involved in extracellular enzymatic activity. Infect Immun 63(8):3015-3020

Iwashita S, Kanegasaki S (1976a) Enzymic and molecular properties of base-plate parts of bacteriophage P22. Eur J Biochem 65(1):87-94. doi:10.1111/j.1432-1033.1976.tb10392.x

Iwashita S, Kanegasaki S (1976b) Deacetylation reaction catalyzed by Salmonella phage c341 and its baseplate parts. J Biol Chem 251(17):5361-5365

Jakobsson E, Jokilammi A, Aalto J, Ollikka P, Lehtonen JV, Hirvonen H, Finne J (2007) Identification of amino acid residues at the active site of endosialidase that dissociate the polysialic acid binding and cleaving activities in Escherichia coli $\mathrm{K} 1$ bacteriophages. Biochem J 405: 465-472. doi:10.1042/bj20070177

Jakobsson E, Schwarzer D, Jokilammi A, Finne J (2015) Endosialidases: versatile tools for the study of polysialic acid. Top Curr Chem 367: 29-73. doi:10.1007/128 2012 349

Kaberdin VR, McDowall KJ (2003) Expanding the use of zymography by the chemical linkage of small, defined substrates to the gel matrix. Genome Res 13:1961-1965. doi:10.1101/gr.1277303

Kanamaru S, Leiman PG, Kostyuchenko VA, Chipman PR, Mesyanzhinov VV, Arisaka F, Rossmann MG (2002) Structure of the cell-puncturing device of bacteriophage T4. Nature 415:553557. doi:10.1038/415553a

Kassa T, Chhibber S (2012) Thermal treatment of the bacteriophage lysate of Klebsiella pneumoniae B5055 as a step for the purification of capsular depolymerase enzyme. J Virol Methods 179(1):135-141. doi:10.1016/j.jviromet.2011.10.011

Kenny JG, McGrath S, Fitzgerald GF, Van Sinderen D (2004) Bacteriophage Tuc2009 encodes a tail-associated cell walldegrading activity. J Bacteriol 186:3480-3491. doi:10.1128/JB. 186.11.3480-3491.2004

Kimura K, Itoh Y (2003) Characterization of poly-gamma-glutamate hydrolase encoded by a bacteriophage genome: possible role in phage infection of Bacillus subtilis encapsulated with poly-gamma- 
glutamate. Appl Environ Microbiol 69(5):2491-2497. doi:10.1128/ aem.69.5.2491-2497.2003

Kivelä HM, Daugelavicius R, Hankkio RH, Bamford JK, Bamford DH (2004) Penetration of membrane-containing double-stranded-DNA bacteriophage PM2 into Pseudoalteromonas hosts. J Bacteriol 186: 5342-5354. doi:10.1128/JB.186.16.5342-5354.2004

Kwiatkowski B, Boschek B, Thiele H, Stirm S (1983) Substrate specificity of two bacteriophage-associated endo-N-acetylneuraminidases. J Virol 45(1):367-374

Lavigne R, Briers Y, Hertveldt K, Robben J, Volckaert G (2004) Identification and characterization of a highly thermostable bacteriophage lysozyme. Cell Mol Life Sci 61:2753-2759. doi:10.1007/ s00018-004-4301-y

Leiman PG, Battisti AJ, Bowman VD, Stummeyer K, Muhlenhoff M, Gerardy-Schahn R, Scholl D, Molineux IJ (2007) The structures of bacteriophages K1E and K1-5 explain processive degradation of polysaccharide capsules and evolution of new host specificities. $\mathrm{J}$ Mol Biol 371(3):836-849. doi:10.1016/j.jmb.2007.05.083

Leiman PG, Molineux IJ (2008) Evolution of a new enzyme activity from the same motif fold. Mol Microbiol 69(2):287-290. doi:10.1111/j. 1365-2958.2008.06241.x

Li X, Koç C, Kühner P, Stierhof YD, Krismer B, Enright MC, Penadés JR, Wolz C, Stehle T, Cambillau C, Peschel A, Xia G (2016) An essential role for the baseplate protein $\mathrm{Gp} 45$ in phage adsorption to Staphylococcus aureus. Sci Rep 6:26455. doi:10.1038/srep26455

Lin TL, Hsieh PF, Huang YT, Lee WC, Tsai YT, Su PA, Pan YJ, Hsu CR, Wu MC, Wang JT (2014) Isolation of a bacteriophage and its depolymerase specific for K1 capsule of Klebsiella pneumoniae: implication in typing and treatment. J Infect Dis 210(11):17341744. doi:10.1093/infdis/jiu332

Lindsay AM, Zhang M, Mitchell Z, Holden MT, Waller AS, Sutcliffe IC, Black GW (2009) The Streptococcus equi prophage-encoded protein SEQ2045 is a hyaluronan-specific hyaluronate lyase that is produced during equine infection. Microbiology 155(Pt 2):443449. doi:10.1099/mic.0.020826-0

Linnerborg M, Weintraub A, Albert MJ, Widmalm G (2001) Depolymerization of the capsular polysaccharide from Vibrio cholerae O139 by a lyase associated with the bacteriophage JA1. Carbohydr Res 333(4):263-269. doi:10.1016/s0008-6215(01)00159-8

Liu Y, Li G, Mo Z, Chai Z, Shang A, Mou H (2014) Properties of Klebsiella phage P13 and associated exopolysaccharide depolymerase. J Ocean Univ China 13(1):163-168. doi:10.1007/ s11802-014-2042-6

Long GS, Bryant JM, Taylor PW, Luzio JP (1995) Complete nucleotidesequence of the gene encoding bacteriophage E endosialidase: implications for K1E endosialidase structure and function. Biochem J 309:543-550

Lu TK, Collins JJ (2007) Dispersing biofilms with engineered enzymatic bacteriophage. Proc Natl Acad Sci U S A 104(27):11197-11202

Machida Y, Miyake K, Hattori K, Yamamoto S, Kawase M, Iijima S (2000) Structure and function of a novel coliphage-associated sialidase. FEMS Microbiol Lett 182(2):333-337. doi:10.1016/ s0378-1097(99)00613-8

Maciejewska B, Roszniowski B, Espaillat A, Kęsik-Szeloch A, Majkowska-Skrobek G, Kropinski AM, Briers Y, Cava F, Lavigne R, Drulis-Kawa Z (2017) Klebsiella phages representing a novel clade of viruses with an unknown DNA modification and biotechnologically interesting enzymes. Appl Microbiol Biotechnol 101: 673-684. doi:10.1007/s00253-016-7928-3

Majkowska-Skrobek G, Łątka A, Berisio R, Maciejewska B, Squeglia F, Romano M, Lavigne R, Struve C, Drulis-Kawa Z (2016) Capsuletargeting depolymerase, derived from Klebsiella KP36 phage, as a tool for the development of anti-virulent strategy. Viruses 8(12):E324

Malnoy M, Faize M, Venisse JS, Geider K, Chevreau E (2005) Expression of viral EPS-depolymerase reduces fire blight susceptibility in transgenic pear. Plant Cell Rep 23:632-638. doi: 10.1007/s00299-004-0855-2

Manoharadas S, Witte A, Bläsi U (2009) Antimicrobial activity of a chimeric enzybiotic towards Staphylococcus aureus. J Biotechnol 139:118-123. doi:10.1016/j.jbiotec.2008.09.003

Martinez-Fleites C, Smith NL, Turkenburg JP, Black GW, Taylor EJ (2009) Structures of two truncated phage-tail hyaluronate lyases from Streptococcus pyogenes serotype M1. Acta Crystallogr Sect F Struct Biol Cryst Commun 65(Pt 10):963-966. doi:10.1107/ s1744309109032813

McCallum KL, Laakso DH, Whitfield C (1989) Use of a bacteriophageencoded glycanase enzyme in the generation of lipopolysaccharide $\mathrm{O}$ side chain deficient mutants of Escherichia coli O9:K30 and Klebsiella O1:K20: role of $\mathrm{O}$ and $\mathrm{K}$ antigens in resistance to complementmediated serum killing. Can J Microbiol 35(11):994-999

McGrath S, Neve H, Seegers JF, Eijlander R, Vegge CS, Brøndsted L, Heller KJ, Fitzgerald GF, Vogensen FK, van Sinderen D (2006) Anatomy of a lactococcal phage tail. J Bacteriol 188:3972-3982. doi:10.1128/JB.00024-06

Mindich L, Lehman J (1979) Cell wall lysin as a component of the bacteriophage $\Phi 6$ virion. J Virol 30:489-496

Mishra P, Akhtar MS, Bhakuni V (2006) Unusual structural features of the bacteriophage-associated hyaluronate lyase (hylp2). J Biol Chem 281(11):7143-7150. doi:10.1074/jbc.M510991200

Moak M, Molineux IJ (2000) Role of the Gp16 lytic transglycosylase motif in bacteriophage T7 virions at the initiation of infection. Mol Microbiol 37:345-355

Moak M, Molineux IJ (2004) Peptidoglycan hydrolytic activities associated with bacteriophage virions. Mol Microbiol 51:1169-1183

Molineux IJ (2001) No syringes please, ejection of phage T7 DNA from the virion is enzyme driven. Mol Microbiol 40:1-8. doi:10.1046/j. 1365-2958.2001.02357.x

Muhlenhoff M, Stummeyer K, Grove M, Sauerborn M, Gerardy-Schahn R (2003) Proteolytic processing and oligomerization of bacteriophage-derived endosialidases. J Biol Chem 278(15): 12634-12644. doi:10.1074/jbc.M212048200

Mushtaq N, Redpath MB, Luzio JP, Taylor PW (2004) Prevention and cure of systemic $E$. coli $\mathrm{K} 1$ infection by modification of the bacterial phenotype. Antimicrob Agents Chemother 48:1503-1508

Mushtaq N, Redpath MB, Luzio JP, Taylor PW (2005) Treatment of experimental $E$. coli infection with recombinant bacteriophage-derived capsule depolymerase. J Antimicrob Chemother 56:160-165

Nilsson N, Malmborg AC, Borrebaeck CA (2000) The phage infection process: a functional role for the distal linker region of bacteriophage protein 3. J Virol 74(9):4229-4235. doi:10.1128/jvi.74.9.4229-4235.2000

Nishima W, Kanamaru S, Arisaka F, Kitao A (2011) Screw motion regulates multiple functions of T4 phage protein gene product 5 during cell puncturing. J Am Chem Soc 133:13571-13576. doi:10.1021/ja204451g

Oliveira H, Melo LDR, Santos SB, Nóbrega FL, Ferreira EC, Cerca N, Azeredo J, Kluskens LD (2013) Molecular aspects and comparative genomics of bacteriophage endolysins. J Virol 87:4558-4570. doi: 10.1128/JVI.03277-12

Pan YJ, Lin TL, Chen CC, Tsai YT, Cheng YH, Chen YY, Hsieh PF, Lin YT, Wang JT (2017) Klebsiella phage $\varphi$ K64-1 encodes multiple depolymerases for multiple host capsular types. J Virol. doi:10. 1128/JVI.02457-16

Pan YJ, Lin TL, Lin YT, Su PA, Chen CT, Hsieh PF, Hsu CR, Chen CC, Hsieh YC, Wang JT (2015) Identification of capsular types in carbapenem-resistant Klebsiella pneumoniae strains by wzc sequencing and implications for capsule depolymerase treatment. Antimicrob Agents Chemother 59:1038-1047. doi:10.1128/AAC.03560-14

Paul VD, Rajagopalan SS, Sundarrajan S, George SE, Asrani JY, Pillai R, Chikkamadaiah R, Durgaiah M, Sriram B, Padmanabhan S (2011) A novel bacteriophage tail-associated muralytic enzyme (TAME) from phage $\mathrm{K}$ and its development into a potent antistaphylococcal protein. BMC Microbiol 11:226. doi:10.1186/1471-2180-11-226 
Petter J, Vimr ER (1993) Complete nucleotide-sequence of the bacteriophage $\mathrm{K} 1 \mathrm{~F}$ tail gene encoding endo-N-acylneuraminidase (endo-N) and comparison to an endo-N homolog in bacteriophage PK1E. J Bacteriol 175(14):4354-4363

Piasecki T, Gula G, Waszczuk K, Drulis-Kawa Z, Gotszalk T (2015) Quartz tuning fork as in situ sensor of bacterial biofilm. Sensors Actuators B 210:825-829. doi:10.1016/j.snb.2014.12.105

Pires DP, Oliveira H, Melo LD, Sillankorva S, Azeredo J (2016) Bacteriophage-encoded depolymerases: their diversity and biotechnological applications. Appl Microbiol Biotechnol 100(5):21412151. doi:10.1007/s00253-015-7247-0

Prehm P, Jann K (1976) Enzymatic action of coliphage omega8 and its possible role in infection. J Virol 19(3):940-949

Proença D, Leandro C, Garcia M, Pimentel M, São-José C (2015) EC300: a phage-based, bacteriolysin-like protein with enhanced antibacterial activity against Enterococcus faecalis. Appl Microbiol Biotechnol 99:5137-5149. doi:10.1007/s00253-015-6483-7

Rashel M, Uchiyama J, Takemura I, Hoshiba H, Ujihara T, Takatsuji H, Honke K, Matsuzaki S (2008) Tail-associated structural protein gp61 of Staphylococcus aureus phage $\Phi$ MR11 has bifunctional lytic activity. FEMS Microbiol Lett 284:9-16. doi:10.1111/j.1574-6968. 2008.01152.x

Rieger D, Freund-Molbert E, Stirm S (1975) Escherichia coli capsule bacteriophages. III. Fragments of bacteriophage 29. J Virol 15(4): 964-975

Rodríguez L, Martínez B, Zhou Y, Rodríguez A, Donovan DM, García P (2011) Lytic activity of the virion-associated peptidoglycan hydrolase HydH5 of Staphylococcus aureus bacteriophage vB SauS-phiIPLA88. BMC Microbiol 11:138. doi:10.1186/1471-2180-11-138

Rodríguez-Rubio L, Gerstmans H, Thorpe S, Mesnage S, Lavigne R, Briers Y (2016) DUF3380 domain from a Salmonella phage endolysin shows potent $\mathrm{N}$-acetylmuramidase activity. Appl Environ Microbiol 82:4975-4981. doi:10.1128/AEM.00446-16

Rodríguez-Rubio L, Martínez B, Donovan DM, Rodríguez A, García P (2013a) Bacteriophage virion-associated peptidoglycan hydrolases: potential new enzybiotics. Crit Rev Microbiol 39:427-434. doi:10. 3109/1040841X.2012.723675

Rodríguez-Rubio L, Martínez B, Rodríguez A, Donovan DM, García P (2012) Enhanced staphylolytic activity of the Staphylococcus aureus bacteriophage vB_SauS-phiIPLA88 HydH5 virion-associated peptidoglycan hydrolase: fusions, deletions, and synergy with LysH5. Appl Environ Microbiol 78:2241-2248. doi:10.1128/AEM.07621-11

Rodríguez-Rubio L, Martínez B, Rodríguez A, Donovan DM, Götz F, García P (2013b) The phage lytic proteins from the Staphylococcus aureus bacteriophage vB_SauS-phiIPLA88 display multiple active catalytic domains and do not trigger staphylococcal resistance. De Lencastre $\mathrm{H}$, ed. PLoS One 8:e64671. doi:10.1371/journal.pone.0064671

Rodríguez-Rubio L, Quiles-Puchalt N, Martínez B, Rodríguez A, Penadés JR, García P (2013c) The peptidoglycan hydrolase of Staphylococcus aureus bacteriophage $\phi 11$ plays a structural role in the viral particle. Appl Environ Microbiol 79:6187-6190. doi: 10.1128/AEM.01388-13

Rydman PS, Bamford DH (2000) Bacteriophage PRD1 DNA entry uses a viral membrane-associated transglycosylase activity. Mol Microbiol 37:356-363. doi:10.1046/j.1365-2958.2000.01996.x

Rydman PS, Bamford DH (2002) The lytic enzyme of bacteriophage PRD1 is associated with the viral membrane. J Bacteriol 184:104 110. doi:10.1128/JB.184.1.104-110.2002

Santos SB, Kropinski AM, Ceyssens PJ, Ackermann HW, Villegas A, Lavigne R, Krylov VN, Carvalho CM, Ferreira EC, Azeredo J (2011) Genomic and proteomic characterization of the broad-host range Salmonella phage PVP-SE1: creation of a new phage genus. J Virol 85(21):11265-11273. doi:10.1128/jvi.01769-10

Saravanan SR, Paul VD, George S, Sundarrajan S, Kumar N, Hebbur M, Kumar N, Veena A, Maheshwari U, Appaiah CB, Chidambaran M, Bhat AG, Hariharan S, Padmanabhan S (2013) Properties and mutation studies of a bacteriophage-derived chimeric recombinant staphylolytic protein P128: comparison to recombinant lysostaphin. Bacteriophage 3:e26564. doi:10.4161/bact.26564

Scheurwater E, Reid CW, Clarke AJ (2008) Lytic transglycosylases: bacterial space-making autolysins. Int J Biochem Cell Biol 40:586-591. doi:10.1016/j.biocel.2007.03.018

Schmid J, Sieber V, Rehm B (2015) Bacterial exopolysaccharides: biosynthesis pathways and engineering strategies. Front Microbiol 6: 496. doi:10.3389/fmicb.2015.00496

Scholl D, Adhya S, Merril CR (2002) Bacteriophage SP6 is closely related to phages $\mathrm{K} 1-5, \mathrm{~K} 5$, and $\mathrm{K} 1 \mathrm{E}$ but encodes a tail protein very similar to that of the distantly related P22. J Bacteriol 184(10):28332836. doi:10.1128/jb.184.10.2833-2836.2002

Scholl D, Cooley M, Williams SR, Gebhart D, Martin D, Bates A, Mandrell R (2009) An engineered R-type pyocin is a highly specific and sensitive bactericidal agent for the food-borne pathogen Escherichia coli O157:H7. Antimicrob Agents Chemother 53: 3074-3080. doi:10.1128/AAC.01660-08

Scholl D, Kieleczawa J, Kemp P, Rush J, Richardson CC, Merril C, Adhya S, Molineux IJ (2004) Genomic analysis of bacteriophages SP6 and K1-5, an estranged subgroup of the T7 supergroup. J Mol Biol 335(5):1151-1171. doi:10.1016/j.jmb.2003.11.035

Scholl D, Rogers S, Adhya S, Merril CR (2001) Bacteriophage K1-5 encodes two different tail fiber proteins, allowing it to infect and replicate on both $\mathrm{K} 1$ and $\mathrm{K} 5$ strains of Escherichia coli. J Virol 75(6):2509-2515. doi:10.1128/jvi.75.6.2509-2515.2001

Schwarzer D, Buettner FF, Browning C, Nazarov S, Rabsch W, Bethe A, Oberbeck A, Bowman VB, Stummeyer K, Muhlenhoff M, Leiman PG, Gerardy-Schahn R (2012) A multivalent adsorption apparatus explains the broad host range of phage phi92: a comprehensive genomic and structural analysis. J Virol 86(19):10384-10398. doi: 10.1128/jvi.00801-12

Serwer P, Wright ET, Hakala KW, Weintraub ST (2008) Evidence for bacteriophage $\mathrm{T} 7$ tail extension during DNA injection. BMC Res Notes 1:36. doi:10.1186/1756-0500-1-36

Serwer P, Wright ET, Liu Z, Jiang W (2014) Length quantization of DNA partially expelled from heads of a bacteriophage T3 mutant. Virology 456-457:157-170. doi:10.1016/j.virol.2014.03.016

Shang A, Liu Y, Wang J, Mo Z, Li G, Mou H (2015) Complete nucleotide sequence of Klebsiella phage P13 and prediction of an EPS depolymerase gene. Virus Genes 50:118-128. doi:10.1007/ s11262-014-1138-9

Smith NL, Taylor EJ, Lindsay AM, Charnock SJ, Turkenburg JP, Dodson EJ, Davies GJ, Black GW (2005) Structure of a group A streptococcal phage-encoded virulence factor reveals a catalytically active triple-stranded beta-helix. Proc Natl Acad Sci U S A 102(49): 17652-17657. doi:10.1073/pnas.0504782102

Steinbacher S, Baxa U, Miller S, Weintraub A, Seckler R, Huber R (1996) Crystal structure of phage P22 tailspike protein complexed with Salmonella sp. O-antigen receptors. Proc Natl Acad Sci U S A 93(20):10584-10588. doi:10.1073/pnas.93.20.10584

Steinbacher S, Miller S, Baxa U, Weintraub A, Seckler R (1997) Interaction of Salmonella phage P22 with its O-antigen receptor studied by X-ray crystallography. Biol Chem 378(3-4):337-343. doi:10.1515/bchm.1997.378.3-4.337

Stirm S, Bessler W, Fehmel F, Freund-Mölbert E (1971) Bacteriophage particles with endo-glycosidase activity. J Virol 8(3):343-346

Stockdale SR, Mahony J, Courtin P, Chapot-Chartier MP, van Pijkeren JP, Britton RA, Neve H, Heller KJ, Aideh B, Vogensen FK, van Sinderen D (2013) The lactococcal phages Tuc2009 and TP901-1 incorporate two alternate forms of their tail fiber into their virions for infection specialization. J Biol Chem 288:5581-5590. doi:10.1074/jbc.M112.444901

Struthers-Schlinke JS, Robins WP, Kemp P, Molineux IJ (2000) The internal head protein Gp16 controls DNA ejection from the bacteriophage T7 virion. J Mol Biol 301:35-45. doi:10.1006/jmbi.2000.3940 
Stummeyer K, Dickmanns A, Muhlenhoff M, Gerardy-Schahn R, Ficner $\mathrm{R}$ (2005) Crystal structure of the polysialic acid-degrading endosialidase of bacteriophage K1F. Nat Struct Mol Biol 12(1): 90-96. doi:10.1038/nsmb874

Stummeyer K, Schwarzer D, Claus H, Vogel U, Gerardy-Schahn R, Muhlenhoff M (2006) Evolution of bacteriophages infecting encapsulated bacteria: lessons from Escherichia coli K1-specific phages. Mol Microbiol 60(5):1123-1135. doi:10.1111/j.1365-2958.2006.05173.x

Sudiarta IP, Fukushima T, Sekiguchi J (2010) Bacillus subtilis CwlP of the SP- $\beta$ prophage has two novel peptidoglycan hydrolase domains, muramidase and cross-linkage digesting dd-endopeptidase. J Biol Chem 285:41232-41243. doi:10.1074/jbc.M110.156273

Sundarrajan S, Raghupatil J, Vipra A, Narasimhaswamy N, Saravanan S, Appaiah C, Poonacha N, Desai S, Nair S, Bhatt RN, Roy P, Chikkamadaiah R, Durgaiah M, Sriram B, Padmanabhan S, Sharma U (2014) Bacteriophage-derived CHAP domain protein, P128, kills Staphylococcus cells by cleaving interpeptide cross-bridge of peptidoglycan. Microbiology 160:2157-2169. doi:10.1099/mic.0.079111-0

Sutherland IW (1995) Polysaccharide lyases. FEMS Microbiol Rev 16(4):323-347

Takác M, Bläsi U (2005) Phage P68 virion-associated protein 17 displays activity against clinical isolates of Staphylococcus aureus. Antimicrob Agents Chemother 49:2934-2940. doi:10.1128/AAC. 49.7.2934-2940.2005

Tang J, Lander GC, Olia AS, Li R, Casjens S, Prevelige P Jr, Cingolani G, Baker TS, Johnson JE (2011) Peering down the barrel of a bacteriophage portal: the genome packaging and release valve in $\mathrm{p} 22$. Structure 19:496-502. doi:10.1016/j.str.2011.02.010

Thompson JE, Pourhossein M, Waterhouse A, Hudson T, Goldrick M, Derrick JP, Roberts IS (2010) The K5 lyase KflA combines a viral tail spike structure with a bacterial polysaccharide lyase mechanism. J Biol Chem 285(31):23963-23969. doi:10.1074/jbc.M110.127571

Thurow H, Niemann H, Rudolph C, Stirm S (1974) Host capsule depolymerase activity of bacteriophage particles active on Klebsiella K20 and K24 strains. Virology 58(1):306-309. doi:10. 1016/0042-6822(74)90166-4

Tomlinson S, Taylor PW (1985) Neuraminidase associated with coliphage E that specifically depolymerizes the Escherichia coli $\mathrm{K} 1$ capsular polysaccharide. J Virol 55(2):374-378

Tote K, Vanden Berghe D, Maes L, Cos P (2008) A new colorimetric microtitre model for the detection of Staphylococcus aureus biofilms. Lett Appl Microbiol 46(2):249-254. doi:10.1111/j.1472765X.2007.02298.x

Verma V, Harjai K, Chhibber S (2009) Restricting ciprofloxacin induced resistant variant formation in biofilm of Klebsiella pneumoniae B5055 by complementary bacteriophage treatment. J Antimicrob Chemiother 64:1212-1218. doi:10.1093/jac/dkp360

Verma V, Harjai K, Chhibber S (2010) Structural changes induced by a lytic bacteriophage make ciprofloxacin effective against older biofilm of Klebsiella pneumoniae. Biofouling 26:729-737. doi:10. 1080/08927014.2010.511196

Vimr ER, Troy FA (1985) Regulation of sialic acid metabolism in Escherichia coli: role of $\mathrm{N}$-acylneuraminate pyruvate-lyase. J Bacteriol 164(2):854-860

Walter M, Fiedler C, Grassl R, Biebl M, Rachel R, Hermo-Parrado XL, Llamas-Saiz AL, Seckler R, Miller S, van Raaij MJ (2008) Structure of the receptor-binding protein of bacteriophage Det7: a podoviral tail spike in a myovirus. J Virol 82(5):2265-2273. doi:10.1128/jvi.01641-07

Waseh S, Hanifi-Moghaddam P, Coleman R, Masotti M, Ryan S, Foss M, MacKenzie R, Henry M, Szymanski CM, Tanha J (2010) Orally administered P22 phage tailspike protein reduces salmonella colonization in chickens: prospects of a novel therapy against bacterial infections. PLoS One 5:e13904. doi:10.1371/journal.pone.0013904

Weigele PR, Scanlon E, King J (2003) Homotrimeric, beta-stranded viral adhesins and tail proteins. J Bacteriol 185(14):4022-4030. doi:10. 1128/jb.185.14.4022-4030.2003

Weinbauer MG (2004) Ecology of prokaryotic viruses. FEMS Microbiol Rev 28:127-181. doi:10.1016/j.femsre.2003.08.001

Wollin R, Eriksson U, Lindberg AA (1981) Salmonella bacteriophage glycanases: endorhamnosidase activity of bacteriophages P27, 9NA, and KB1. J Virol 38(3):1025-1033

Wong TY, Preston LA, Schiller NL (2000) Alginate lyase: review of major sources and enzyme characteristics, structure-function analysis, biological roles, and applications. Annu Rev Microbiol 54:289340. doi:10.1146/annurev.micro.54.1.289

Yan J, Mao J, Xie J (2014) Bacteriophage polysaccharide depolymerases and biomedical applications. BioDrugs 28(3):265-274. doi:10. 1007/s40259-013-0081-y

Yap ML, Rossmann MG (2014) Structure and function of bacteriophage T4. Future Microbiol 9:1319-1327. doi:10.2217/fmb.14.91

Young R (1992) Bacteriophage lysis: mechanism and regulation. Microbiol Rev 56:430-481

Yurewicz EC, Ghalambor MA, Duckworth DH, Heath EC (1971) Catalytic and molecular properties of a phage-induced capsular polysaccharide depolymerase. J Biol Chem 246(18):5607-5616

Zelmer A, Martin MJ, Gundogdu O, Birchenough G, Lever R, Wren BW, Luzio JP, Taylor PW (2010) Administration of capsule-selective endosialidase $\mathrm{E}$ minimizes upregulation of organ gene expression induced by experimental systemic infection with Escherichia coli K1. Microbiology 156:22052215. doi: $10.1099 / \mathrm{mic} .0 .036145-0$

Zivanovic Y, Confalonieri F, Ponchon L, Lurz R, Chami M, Flayhan A, Renouard M, Huet A, Decottignies P, Davidson AR, Breyton C, Boulanger P (2014) Insights into bacteriophage T5 structure from analysis of its morphogenesis genes and protein components. J Virol 88:1162-1174. doi:10.1128/JVI.02262-13 